\title{
Dalton Transactions
}

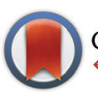

CrossMark

Cite this: Dalton Trans., 2017, 46 2699

Received 19th October 2016, Accepted 17th January 2017

DOI: $10.1039 / \mathrm{c} 6 \mathrm{dt} 04012 \mathrm{~h}$

rsc.li/dalton

\section{Determination of ZFS parameters from the EPR spectra of mono-, di- and trinuclear $\mathrm{Mn}^{\prime \prime}$ complexes: impact of magnetic coupling $\dagger$}

\author{
Luis Escriche-Tur, ${ }^{a, b}$ Mercè Font-Bardia, ${ }^{c}$ Belén Albela ${ }^{b}$ and Montserrat Corbella*a,d
}

A family of new $\mathrm{Mn}^{\prime \prime}$ compounds, consisting of seven dinuclear, three mononuclear, and four trinuclear ones, were synthesised using benzoic acid derivatives $n-\mathrm{RC}_{6} \mathrm{H}_{4} \mathrm{COOH}$, where $n-\mathrm{R}=2-\mathrm{MeO}, 3-\mathrm{MeO}$, 4- $\mathrm{MeO}$, or $4{ }^{t} \mathrm{Bu}$, and 2,2'-bipyridine (bpy) or 1,10-phenantroline (phen) as blocking ligands. The crystal structures of nine of these compounds and the magnetic studies of all of them are reported here. Each type of compound was formed depending on the presence or absence of $\mathrm{ClO}_{4}{ }^{-}$ions, the solvent used, and/or the presence of a small amount of water in the reaction medium. The use of the tert-buthylbenzoate ligand gave unexpected results, very likely due to the steric hindrance caused by the voluminous ${ }^{t} \mathrm{Bu}$ groups. The EPR spectra of each type of compound give some peculiar features that allow its identification. Attempts to fit these spectra have been made in order to determine the ZFS parameters, $D$ and $E$, of the $\mathrm{Mn}^{\prime \prime}$ ion (for mononuclear and dinuclear systems) or of the ground state (for trinuclear systems). For trinuclear systems, the single-ion ZFS parameters estimated from those of the ground state provided a good simulation of the EPR spectra of these compounds. The EPR signals observed in each case have been rationalised according to the energy level distribution and the plausible population in the excited states. In some particular situations, the sign of $D_{\mathrm{Mn}}$ could be determined from the fit of the EPR spectra of the antiferromagnetic dinuclear compounds, the source of the difference between the spectra lying in the second excited state.

\section{Introduction}

$\mathrm{Mn}^{\mathrm{II}}$ complexes are widely present in numerous enzymes, as an essential ingredient of their active site. ${ }^{1} \mathrm{Mn}^{\mathrm{II}}$ ions can be implicated in both redox and non-redox processes, acting as

\footnotetext{
${ }^{a}$ Departament de Química Inorgànica i Orgànica (Secció inorgánica), Universitat de Barcelona, C/Martí i Franquès 1-11, 08028 Barcelona, Spain.

E-mail: luis.escrichetur@gmail.com, montse.corbella@qi.ub.es

${ }^{b}$ Laboratoire de Chimie, ENS de Lyon, Université de Lyon, 46 Allée d'Italie, 69364 Lyon Cedex 07, France

${ }^{c}$ Cristal-lografia, Mineralogia i Dipòsits Minerals, Universitat de Barcelona, Martí i Franquès s/n, 08028 Barcelona, Spain

${ }^{d}$ Institud de Nanociència $i$ Nanotecnologia de la Universitat de Barcelona $\left(I N^{2} U B\right)$, Av. Joan XXIII s/n, 08028 Barcelona, Spain

$\dagger$ Electronic supplementary information (ESI) available: Tables containing crystal data and structure refinement details, figure of the crystal structures of the cationic complexes of compounds $\mathbf{1 - 3}, \mathbf{5 - 9}$, and $\mathbf{1 2}$, tables with selected structural parameters for compounds 1-3, 5-9, and 12, $\chi_{\mathrm{M}} T$ versus $T$ and $\chi_{\mathrm{M}}$ versus $T$ plots for compounds $\mathbf{4}$ and $\mathbf{5}$, and several figures showing simulations of EPR spectra with diferent $2 J, D$, and $E$ values and at different temperatures. X-ray crystallographic files in CIF format for the structure determination of compounds 1-3, 5-9, and 12. CCDC 1507565-1507573. For ESI and crystallographic data in CIF or other electronic format see DOI: 10.1039/c6dt04012h
}

catalysts or having a structural role. ${ }^{2-5}$ Owing to its single-ion high spin $(S=5 / 2)$ and comparable size, $\mathrm{Mn}^{\mathrm{II}}$ is commonly used as a probe to replace diamagnetic ions, such as $\mathrm{Mg}^{2+6,7}$ in other biological systems. Additionally, some $\mathrm{Mn}^{\mathrm{II}}$ compounds can be used as catalysts in several industrial processes, commonly for the epoxidation of olefins, ${ }^{8-12}$ making them good candidates to replace $2^{\text {nd }}$ and $3^{\text {rd }}$ row transition metal ions in oxidation catalysis.

From the analyses of EPR spectra of $\mathrm{Mn}^{\mathrm{II}}$ compounds, important information can be extracted, since the splitting of the magnetic sublevels will depend on the zero-field splitting (ZFS) parameters, $D$ and $E$. Indeed, even a slight distortion from a regular octahedral environment can result in significant ZFS parameters and highly complicated EPR spectra. ${ }^{13}$ Furthermore, it is well known that, for several transition metal ions, the ZFS can probe their structural and electrostatic environments. ${ }^{14}$ For example, the $\mathrm{ZFS}$ for $\mathrm{Mn}^{\mathrm{II}}$ ions is larger when it is bonded to halide ligands. ${ }^{13,15-22}$ It also depends on the coordination number, since pentacoordinated ions display greater axial ZFS parameters $\left(|D|=0.25-0.30 \mathrm{~cm}^{-1}\right)$ than hexacoordinated ones $\left(|D|=0.0008-0.1750 \mathrm{~cm}^{-1}\right) .{ }^{23,24}$ Moreover, the ZFS parameters could also be affected by the ratio between the $\mathrm{N}$ - and O-based ligands. ${ }^{25}$ 
The reaction between $\mathrm{Mn}^{\mathrm{II}}$ carboxylate and bidentate ligands (NN), such as 2,2'-bipyridine (bpy) and 1,10-phenanthroline (phen), leads to the formation of $\mathrm{Mn}^{\mathrm{II}}$ compounds with different nuclearity: mononuclear, dinuclear, trinuclear, or 1D systems. ${ }^{26,27}$ The carboxylate groups display a wide variety of coordination modes, such as monodentate terminal, chelating, bidentate bridging, and monodentate bridging modes. Particularly in these compounds, the carboxylate ligands could bridge the $\mathrm{Mn}^{\mathrm{II}}$ ions in $\mu_{1,1}$ or $\mu_{1,3}$ coordination modes, and in the latter case in either a $s y n-s y n$ or $s y n-a n t i$ conformation.

The magnetic interaction between neighboring $\mathrm{Mn}^{\mathrm{II}}$ ions depends on the coordination mode of the carboxylate ligand. For instance, dinuclear compounds with $\mu_{1,1}$-carboxylate bridges present a ferromagnetic interaction $(S=5$ ground state), while those with $\mu_{1,3}$-carboxylate bridges show an antiferromagnetic interaction ( $S=0$ ground state). ${ }^{26}$

We herein present three kinds of compounds: dinuclear $\left[\left\{\mathrm{Mn}(\mathrm{NN})_{2}\right\}_{2}\left(\mu-n-\mathrm{RC}_{6} \mathrm{H}_{4} \mathrm{COO}\right)_{2}\right]\left(\mathrm{ClO}_{4}\right)_{2} \quad(1-7), \quad$ mononuclear $\left[\mathrm{Mn}(\mathrm{NN})_{3-m}\left(n-\mathrm{RC}_{6} \mathrm{H}_{4} \mathrm{COO}\right)_{m}\left(\mathrm{H}_{2} \mathrm{O}\right)_{x}\right]\left(\mathrm{ClO}_{4}\right)_{2-m}$ (with $m=1$ or 2 and $x=0,1$, or 2) (8-10), and trinuclear $\left[\mathrm{Mn}_{3}(\mathrm{NN})_{2}(\mu-n-\right.$ $\left.\left.\mathrm{RC}_{6} \mathrm{H}_{4} \mathrm{COO}\right)_{6}\right]$ (11-14) compounds, synthesised with $n$ - $\mathrm{MeOC}_{6} \mathrm{H}_{4} \mathrm{COO}^{-}(n=2,3,4)$ or $4{ }^{-}{ }^{t} \mathrm{BuC}_{6} \mathrm{H}_{4} \mathrm{COO}^{-}$ligands, and $\mathrm{NN}=$ bpy or phen. The magnetic properties of these compounds have been studied and their EPR spectra have been deeply analysed. Moreover a qualitative rationalisation of the displayed EPR signals has been performed. Fits of these spectra have been attempted, leading to a reasonable determination of the zero field splitting parameters, $D$ and $E$. The Zeeman plots of the dinuclear compounds have been deeply analysed to provide a better understanding of the EPR spectra.

\section{Experimental section}

\section{Synthesis}

All manipulations were performed under aerobic conditions. Reagents and solvents were obtained from commercial sources and used without further purification. Caution! Perchlorate salts of compounds containing organic ligands are potentially explosive. Only small quantities of these compounds should be prepared. $\mathrm{Mn}\left(n-\mathrm{MeOC}_{6} \mathrm{H}_{4} \mathrm{COO}\right)_{2} \cdot x \mathrm{H}_{2} \mathrm{O}(n=2$ and 4) was obtained from the reaction between $\mathrm{MnCO}_{3}$ and $n$ - $\mathrm{MeOC}_{6} \mathrm{H}_{4} \mathrm{COOH}$ in boiling water. After several hours, the solution was filtered and concentrated to give a pale pink precipitate of the desired product. For $n=2, \mathrm{C}_{16} \mathrm{H}_{14} \mathrm{MnO}_{6}$ (M.W. = $357.16 \mathrm{~g} \mathrm{~mol}^{-1}$ ). Anal. Calcd (\%): C, 53.80; H, 3.95. Found (\%): $\mathrm{C}, 52.20 ; \mathrm{H}, 3.90$. For $n=4, \mathrm{C}_{16} \mathrm{H}_{14} \mathrm{MnO}_{6} \cdot 2 \mathrm{H}_{2} \mathrm{O}$ (M.W. $=$ $393.25 \mathrm{~g} \mathrm{~mol}^{-1}$ ). Anal. Calcd (\%): C, 48.87; H, 4.61. Found (\%): $\mathrm{C}, 49.2 ; \mathrm{H}, 4.70 . \mathrm{Mn}\left(3-\mathrm{MeOC}_{6} \mathrm{H}_{4} \mathrm{COO}\right)_{2} \cdot 2 / 3 \mathrm{EtOH}$ was obtained following the same procedure but assisting the crystallisation by adding $\mathrm{EtOH}$ to the mother liquor and leaving it undisturbed in the refrigerator. $\mathrm{C}_{16} \mathrm{H}_{14} \mathrm{MnO}_{6} \cdot 2 / 3 \mathrm{EtOH}$ (M.W. = $387.93 \mathrm{~g} \mathrm{~mol}^{-1}$ ). Anal. Calcd (\%): C, 53.67; H, 4.67. Found (\%): C, 53.37; $\mathrm{H}$, 4.80. $\mathrm{Mn}\left(4-{ }^{t} \mathrm{BuC}_{6} \mathrm{H}_{4} \mathrm{COO}\right)_{2} \cdot 3 \mathrm{H}_{2} \mathrm{O}$ was obtained following the same procedure as for $n-\mathrm{R}=2-\mathrm{MeO}$ and $4-\mathrm{MeO}$ but using $\mathrm{Mn}(\mathrm{AcO})_{2}$ instead of $\mathrm{MnCO}_{3} \cdot \mathrm{C}_{22} \mathrm{H}_{26} \mathrm{MnO}_{4}$ (M.W. = $463.42 \mathrm{~g} \mathrm{~mol}^{-1}$ ). Anal. Calcd (\%): C, 57.02; H, 6.96. Found (\%): C, 57.70; H, 6.80.

$\left[\left\{\mathrm{Mn}(\mathrm{bpy})_{2}\right\}_{2}\left(\boldsymbol{\mu}-2-\mathrm{MeOC}_{6} \mathrm{H}_{4} \mathrm{COO}\right)_{2}\right]\left(\mathrm{ClO}_{4}\right)_{2}$ $\left.\mathrm{MeOC}_{6} \mathrm{H}_{4} \mathrm{COO}\right)_{2}(0.30 \mathrm{mmol}, 0.11 \mathrm{~g})$ was dissolved in an EtOH : $\mathrm{H}_{2} \mathrm{O} 1: 1(\mathrm{v} / \mathrm{v})$ mixture $(30 \mathrm{~mL})$ by stirring for around $24 \mathrm{~h}$. Then, a solution of $\mathrm{NaClO}_{4}(0.33 \mathrm{mmol}, 0.041 \mathrm{~g})$ in EtOH : $\mathrm{H}_{2} \mathrm{O} 1: 1(\mathrm{v} / \mathrm{v})(10 \mathrm{~mL})$ was added to the previous one. Meanwhile, 2,2'-bipyridine (bpy) (0.72 mmol, $0.11 \mathrm{~g}$ ) was dissolved in EtOH $(10 \mathrm{~mL})$ and added to the previous solution. The resulting yellow solution (solvent: $50 \mathrm{~mL}$ of EtOH: $\mathrm{H}_{2} \mathrm{O}$ $3: 2$ ) was stirred for 15 minutes and filtered to separate any possible impurity. Then, the solution was left undisturbed at room temperature. The crystallisation of the product begins after a month of slow evaporation and may last up to six months. During this time, neither oxidation nor decomposition of the sample was observed. Yield: $65 \%$. X-ray suitable single-crystals were obtained from the mother liquor. $\mathrm{C}_{56} \mathrm{H}_{46} \mathrm{Cl}_{2} \mathrm{Mn}_{2} \mathrm{~N}_{8} \mathrm{O}_{14}$ (M.W. = $1235.79 \mathrm{~g} \mathrm{~mol}^{-1}$ ). Anal. Calcd (\%): C, 54.43; H, 3.75; N, 9.07. Found (\%): C, 54.49; H, 3.90; N, 9.19. IR ( $\left.\mathrm{cm}^{-1}\right)$ : 3435 (br), $3114(\mathrm{w}), 3078(\mathrm{w}), 3007(\mathrm{w}), 2981$ (w), 2950 (w), 2841 (w), 1592 (s), 1567 (s), 1489 (m), 1472 (m), 1438 (s), 1403 (s), 1313 (m), 1280 (m), 1245 (m), 1193 (w) 1171 (m), 1092 (br,s), $1015(\mathrm{~s}), 847(\mathrm{~m}), 774(\mathrm{~m}), 750(\mathrm{~m}), 737(\mathrm{~m})$, $647(\mathrm{w}), 622(\mathrm{~m}), 572(\mathrm{w}), 520(\mathrm{w}), 410(\mathrm{~m})$.

$\left[\left\{\mathrm{Mn}(\mathrm{bpy})_{2}\right\}_{2}\left(\boldsymbol{\mu}-3-\mathrm{MeOC}_{6} \mathrm{H}_{4} \mathrm{COO}\right)_{2}\right]\left(\mathrm{ClO}_{4}\right)_{2} \quad$ (2). $\mathrm{Mn}(3-$ $\left.\mathrm{MeOC}_{6} \mathrm{H}_{4} \mathrm{COO}\right)_{6} \cdot 2 / 3 \mathrm{EtOH}(0.23 \mathrm{mmol}, 0.09 \mathrm{~g})$ and $\mathrm{Mn}\left(\mathrm{ClO}_{4}\right)_{2}$ $(0.25 \mathrm{mmol}, 0.09 \mathrm{~g})$ were dissolved in a mixture of $\mathrm{CH}_{3} \mathrm{CN}$ (15 mL) and $\mathrm{H}_{2} \mathrm{O}(5 \mathrm{~mL})$. Then, bpy (1.0 mmol, $\left.0.16 \mathrm{~g}\right)$ was dissolved in $\mathrm{CH}_{3} \mathrm{CN}(10 \mathrm{~mL})$ and added to the previous solution, giving a yellow solution (total volume $\sim 40 \mathrm{~mL}$ ). After 7 months of slow evaporation, yellow crystals were filtered and washed with cold $\mathrm{CH}_{3} \mathrm{CN}$. Yield: 76\%. X-ray suitable single-crystals were isolated from the mother liquor. $\mathrm{C}_{56} \mathrm{H}_{46} \mathrm{Cl}_{2} \mathrm{Mn}_{2} \mathrm{~N}_{8} \mathrm{O}_{14}$ (M.W. = $1235.79 \mathrm{~g} \mathrm{~mol}^{-1}$ ). Anal. Calcd (\%): C, 54.43; H, 3.75; N, 9.07. Found (\%): C, 54.19; H, 3.83; N, 9.18. IR $\left(\mathrm{cm}^{-1}\right): 3446$ (br), $3112(\mathrm{w}), 3087(\mathrm{w}), 2935$ (w), 2834 (w), 1602 (s), 1575 (s), 1492 (w), 1474 (m), $1452(\mathrm{~m}), 1438$ (s), 1397 (s), 1312 (m), 1279 (m), 1244 (m), 1161 (w) 1086 (br,s), 1046 (m), 1015 (w), 814 (w), $768(\mathrm{~s}), 738(\mathrm{~m}), 683(\mathrm{w}), 666(\mathrm{w}), 648(\mathrm{w}), 622(\mathrm{~m}), 558(\mathrm{w})$, $422(\mathrm{~m})$.

$\left[\left\{\mathrm{Mn}(\mathrm{bpy})_{2}\right\}_{2}\left(\boldsymbol{\mu}-4-\mathrm{MeOC}_{6} \mathrm{H}_{4} \mathrm{COO}\right)_{2}\right]\left(\mathrm{ClO}_{4}\right)_{2}$ $\left.\mathrm{MeOC}_{6} \mathrm{H}_{4} \mathrm{COO}\right)_{2} \cdot 2 \mathrm{H}_{2} \mathrm{O}(0.50 \mathrm{mmol}, 0.20 \mathrm{~g})$ was dissolved in $\mathrm{CH}_{3} \mathrm{CN}: \mathrm{H}_{2} \mathrm{O} 1: 1(\mathrm{v} / \mathrm{v})(20 \mathrm{~mL})$, to which a solution of $\mathrm{NaClO}_{4}$ (0.50 mmol, $0.073 \mathrm{~g}$ ) in $\mathrm{CH}_{3} \mathrm{CN}: \mathrm{H}_{2} \mathrm{O} 1: 1(10 \mathrm{~mL})$ was added. Then, another solution of bpy $(1.20 \mathrm{mmol}, 0.19 \mathrm{~g})$ in $\mathrm{CH}_{3} \mathrm{CN}: \mathrm{H}_{2} \mathrm{O} 1: 1(10 \mathrm{~mL})$ was also added. The resulting yellow solution was left undisturbed at room temperature to obtain yellow needles after 3 weeks of slow evaporation. Yield: $82 \%$. Single-crystals suitable for X-ray characterisation were obtained after two months of keeping the solution in the fridge. $\mathrm{C}_{56} \mathrm{H}_{46} \mathrm{Cl}_{2} \mathrm{Mn}_{2} \mathrm{~N}_{8} \mathrm{O}_{14}$ (M.W. = $1235.79 \mathrm{~g} \mathrm{~mol}^{-1}$ ). Anal. Calcd (\%): C, 54.43; H, 3.75; N, 9.07. Found (\%): C, 54.31; H, 3.81; N, 9.18.

$\left[\left\{\mathrm{Mn}(\text { phen })_{2}\right\}_{2}\left(\boldsymbol{\mu}-2-\mathrm{MeOC}_{6} \mathbf{H}_{4} \mathbf{C O O}\right)_{2}\right]\left(\mathrm{ClO}_{4}\right)_{2} \quad$ (4). $\quad \mathrm{Mn}(2-$ $\left.\mathrm{MeOC}_{6} \mathrm{H}_{4} \mathrm{COO}\right)_{2}(0.12 \mathrm{mmol}, 0.042 \mathrm{~g})$ was dissolved in an 
EtOH : $\mathrm{H}_{2} \mathrm{O} 3: 2(\mathrm{v} / \mathrm{v})$ mixture $(25 \mathrm{~mL})$ by stirring for around $24 \mathrm{~h}$. Then, a solution of $\mathrm{NaClO}_{4}(0.12 \mathrm{mmol}, 0.014 \mathrm{~g})$ in EtOH : $\mathrm{H}_{2} \mathrm{O}(\mathrm{v} / \mathrm{v})(10 \mathrm{~mL})$ was added to the previous one. Meanwhile, 2,2'-bipyridine (bpy) ( $0.23 \mathrm{mmol}, 0.046 \mathrm{~g}$ ) was dissolved in EtOH $(10 \mathrm{~mL})$ and added to the other solution. The resulting yellow solution (solvent: $45 \mathrm{~mL}$ of EtOH: $\mathrm{H}_{2} \mathrm{O} 4: 5$ ) was stirred for 15 minutes and filtered to separate any possible impurity. After 2 weeks of slow evaporation at room temperature, big yellow crystals were collected by filtration and washed with EtOH. Yield: $80 \% . \mathrm{C}_{64} \mathrm{H}_{46} \mathrm{Cl}_{2} \mathrm{Mn}_{2} \mathrm{~N}_{8} \mathrm{O}_{14}$ (M.W. $=1331.88$ $\mathrm{g} \mathrm{mol}^{-1}$ ). Anal. Calcd (\%): C, 57.71; H, 3.48; N, 8.41. Found (\%): C, 56.47; H, 3.37; N, 8.20. IR ( $\left.\mathrm{cm}^{-1}\right): 3442$ (br), 3065 (w), 2964 (w), 2832 (w), 1610 (s), 1588 (s), 1564 (s), 1513 (m), 1492 (w), $1458(\mathrm{w}), 1223(\mathrm{~m}), 1390(\mathrm{~m}), 1340(\mathrm{w}), 1300(\mathrm{w}), 1274(\mathrm{w})$, 1241 (w), 1153 (m) 1100 (vs), 1015 (m), 847 (s), 778 (w), $759(\mathrm{w}), 730(\mathrm{~m}), 660(\mathrm{w}), 642(\mathrm{w}), 615(\mathrm{~m}), 567(\mathrm{w}), 419(\mathrm{w})$.

\section{$\left[\left\{\mathrm{Mn}(\text { phen })_{2}\right\}_{2}\left(\boldsymbol{\mu}-4-{ }^{t} \mathrm{BuC}_{6} \mathrm{H}_{4} \mathrm{COO}\right)_{2}\right]\left(\mathrm{ClO}_{4}\right)_{2}$}

(5). $\quad \mathrm{Mn}(4-$ $\left.{ }^{t} \mathrm{BuC}_{6} \mathrm{H}_{4} \mathrm{COO}\right)_{2} \cdot 3 \mathrm{H}_{2} \mathrm{O}(0.12 \mathrm{mmol}, 0.054 \mathrm{~g})$ and $\mathrm{NaClO}_{4}$ $(0.12 \mathrm{mmol}, 0.014 \mathrm{~g})$ were dissolved in absolute EtOH $(10 \mathrm{~mL})$. Phen (0.23 mmol, $0.046 \mathrm{~g}$ ) dissolved in absolute EtOH was added to the previous solution and the mixture was stirred for 10 minutes. Then, $\mathrm{H}_{2} \mathrm{O}(4 \mathrm{~mL})$ was added and the solution was left undisturbed at room temperature. After two weeks of slow evaporation, yellow crystals were filtered and washed with EtOH. Yield: $18 \%$. X-ray suitable crystals were obtained from the mother liquor. IR $\left(\mathrm{cm}^{-1}\right)$ : $3430(\mathrm{br}), 3071(\mathrm{w}), 2950(\mathrm{w})$, 1609 (s), 1558 (m), 1515 (m), 1394 (s), 1339 (w), 1298 (w), 1267 (w), 1194 (w), 1152 (m), 1099 (vs), 1012 (w), 850 (s), $792(\mathrm{~m}), 775(\mathrm{~m}), 731(\mathrm{~s}), 623(\mathrm{~s}), 543(\mathrm{w}), 420(\mathrm{w})$.

$\left[\left\{\mathrm{Mn}(\text { phen })_{2}\right\}_{2}\left(\boldsymbol{\mu}-3-\mathrm{MeOC}_{6} \mathrm{H}_{4} \mathrm{COO}\right)_{2}\right]\left(\mathrm{ClO}_{4}\right)_{2} \quad$ (6). $\mathrm{Mn}(3-$ $\left.\mathrm{MeOC}_{6} \mathrm{H}_{4} \mathrm{COO}\right)_{6} \cdot 2 / 3 \mathrm{EtOH}(0.31 \mathrm{mmol}, 0.12 \mathrm{~g})$ and $\mathrm{NaClO}_{4}$ ( $0.30 \mathrm{mmol}, 0.040 \mathrm{~g}$ ) were dissolved in $\mathrm{MeOH}$. Then, 1,10-phenantroline (phen) (0.60 mmol, $0.12 \mathrm{~g}$ ) was dissolved in $\mathrm{MeOH}$ and added to the previous mixture, giving a yellow solution (total volume $\sim 50 \mathrm{~mL}$ ). After stirring for 15 minutes, the solution was filtered to separate any possible impurities. After two weeks of slow evaporation at room temperature, yellow crystals were filtered and washed with $\mathrm{MeOH}$. Yield: $80 \%$. $\mathrm{C}_{64} \mathrm{H}_{46} \mathrm{Cl}_{2} \mathrm{Mn}_{2} \mathrm{~N}_{8} \mathrm{O}_{14}$ (M.W. $=1331.88 \mathrm{~g} \mathrm{~mol}^{-1}$ ). Anal. Calcd (\%): C, 57.71; H, 3.48; N, 8.41. Found (\%): C, 55.89; H, 3.55; N, 8.40. IR ( $\left.\mathrm{cm}^{-1}\right)$ : 3435 (br), 3062 (w), 2999 (w), 2940 (w), 2840 (w), 1618 (s), 1577 (m), 1520 (m), 1456 (w), 1428 (s), 1306 (s), 1283 (m), 1231 (w), 1150 (m) 1186 (vs), 1043 (m), 852 (s), 775 (m), 731 (s), 622 (s) $423(\mathrm{w})$.

$\left[\left\{\mathrm{Mn}(\text { phen })_{2}\right\}_{2}\left(\boldsymbol{\mu}-4-\mathrm{MeOC}_{6} \mathrm{H}_{4} \mathrm{COO}\right)_{2}\right]\left(\mathrm{ClO}_{4}\right)_{2} \quad$ (7). $\mathrm{Mn}(4-$ $\left.\mathrm{MeOC}_{6} \mathrm{H}_{4} \mathrm{COO}\right)_{2} \cdot 2 \mathrm{H}_{2} \mathrm{O}(0.30 \mathrm{mmol}, 0.14 \mathrm{~g})$ and $\mathrm{NaClO}_{4}$ $(0.12 \mathrm{mmol}, 0.014 \mathrm{~g})$ were dissolved in a $\mathrm{CH}_{3} \mathrm{CN}: \mathrm{H}_{2} \mathrm{O}$ $2: 1$ mixture $(15 \mathrm{~mL})$. Then, a solution of phen $(0.60 \mathrm{mmol}$, $0.12 \mathrm{~g}$ ) in $\mathrm{CH}_{3} \mathrm{CN}(5 \mathrm{~mL})$ was added to the previous solution and the mixture was stirred for 15 minutes. Afterwards, $\mathrm{MeOH}$ $(30 \mathrm{~mL})$ was added. After a month of slow evaporation yellow single-crystals were filtered and washed with $\mathrm{MeOH}$. Yield: 95\%. $\mathrm{C}_{64} \mathrm{H}_{46} \mathrm{Cl}_{2} \mathrm{Mn}_{2} \mathrm{~N}_{8} \mathrm{O}_{14}$ (M.W. $=1331.88 \mathrm{~g} \mathrm{~mol}{ }^{-1}$ ). Anal. Calcd (\%): C, 57.71; H, 3.48; N, 8.41. Found (\%): C, 57.34; H, 3.59; N, 8.48. IR ( $\left.\mathrm{cm}^{-1}\right)$ : 3435 (br), 3062 (w), 2999 (w), 2941 (w), 2840 (w), 1618 (s), 1578 (s), 1521 (s), 1456 (w), 1482 (s),
1306 (s), 1231 (m), 1150 (m), 1086 (vs), 1042 (m), 852 (s), $776(\mathrm{~m}), 731(\mathrm{~s}), 722(\mathrm{~s}), 423(\mathrm{w})$.

$\left[\mathrm{Mn}\left(\mathrm{H}_{2} \mathrm{O}\right)\left(3-\mathrm{MeOC}_{6} \mathrm{H}_{4} \mathrm{COO}\right)(\text { phen })_{2}\right] \mathrm{ClO}_{4}$ $\left.\mathrm{MeOC}_{6} \mathrm{H}_{4} \mathrm{COO}\right)_{6} \cdot 2 / 3 \mathrm{EtOH}(0.12 \mathrm{mmol}, 0.045 \mathrm{~g})$ and $\mathrm{NaClO}_{4}$ $(0.12 \mathrm{mmol}, 0.014 \mathrm{~g})$ were dissolved in $\mathrm{CH}_{3} \mathrm{CN}(10 \mathrm{~mL}) \cdot \mathrm{H}_{2} \mathrm{O}$ ( $2 \mathrm{~mL}$ ) was added to assist the complete dissolution of all reagents. Then, phen (0.12 mmol, $0.046 \mathrm{~g}$ ) dissolved in $\mathrm{CH}_{3} \mathrm{CN}$ $(10 \mathrm{~mL})$ was added to the previous solution. After 20 days of slow evaporation yellow crystals were filtered and washed with $\mathrm{CH}_{3} \mathrm{CN}$. Yield: $80 \%$. X-ray suitable crystals were obtained from the mother liquor. $\mathrm{C}_{32} \mathrm{H}_{25} \mathrm{ClMnN}_{4} \mathrm{O}_{8}$ (M.W. $=683.95 \mathrm{~g} \mathrm{~mol}^{-1}$ ). Anal. Calcd (\%): C, 56.19; H, 3.68; N, 8.19. Found (\%): C, 55.85; H, 3.77 N, 8.23. IR ( $\left.\mathrm{cm}^{-1}\right): 3442(\mathrm{~m}), 3063(\mathrm{w}), 3008(\mathrm{w})$, 2935 (w), 2837 (w), 1558 (m), 1517 (s), 1425 (s), 1379 (s), 1341 (w), $1315(\mathrm{w}), 1280(\mathrm{w}), 1249(\mathrm{~m}), 1098(\mathrm{~s}), 1035(\mathrm{~m}), 854(\mathrm{~s})$, $772(\mathrm{~s}), 724(\mathrm{~s}), 623(\mathrm{~m}), 421(\mathrm{~m})$.

$\left[\mathrm{Mn}\left(\mathrm{H}_{2} \mathrm{O}\right)_{2}\left(2-\mathrm{MeOC}_{6} \mathbf{H}_{4} \mathbf{C O O}\right)_{2}\right.$ (phen)] (9). Phen (0.12 mmol, $0.023 \mathrm{~g})$ dissolved in EtOH $(10 \mathrm{~mL})$ was added to a solution of $\mathrm{Mn}\left(2-\mathrm{MeOC}_{6} \mathrm{H}_{4} \mathrm{COO}\right)_{2}(0.12 \mathrm{mmol}, 0.042 \mathrm{~g})$ in EtOH : $\mathrm{H}_{2} \mathrm{O} 4: 3$ $(35 \mathrm{~mL})$. The resulting pale yellow solution was stirred for 15 minutes. After 1 month of slow evaporation, yellow crystals were filtered and washed with EtOH. Yield: 65\%. X-ray suitable single-crystals were obtained from the mother liquor. $\mathrm{C}_{28} \mathrm{H}_{26} \mathrm{MnN}_{2} \mathrm{O}_{8}$ (M.W. = $573.45 \mathrm{~g} \mathrm{~mol}^{-1}$ ). Anal. Calcd (\%): C, 58.64; H, 4.57; N, 4.89. Found (\%): C, 58.56; H, 4.69; N, 5.03. IR (cm $\left.{ }^{-1}\right): 3448$ (s), 2967 (w), 2939 (w), 2837 (w), 1603 (s), 1544 (s), 1513 (m), 1423 (m), 1376 (s), 1292 (w), 1270 (m), 1236 (m), $1186(\mathrm{w}), 1163(\mathrm{w}), 1099(\mathrm{~m}), 1057$ (w), $1019(\mathrm{~m}), 859(\mathrm{~m})$, $832(\mathrm{~m}), 767$ (s), $733(\mathrm{~m}), 660(\mathrm{w}), 637$ (w), $554(\mathrm{w}), 443(\mathrm{w})$.

$\left[\mathrm{Mn}(\mathrm{bpy})\left(4^{t}{ }^{t} \mathrm{BuC}_{6} \mathrm{H}_{4} \mathrm{COO}\right)_{2}\right] \cdot \mathrm{H}_{2} \mathrm{O}$ (10). A solution of bpy ( $2 \mathrm{mmol}, 0.33 \mathrm{~g}$ ) in $\mathrm{CH}_{3} \mathrm{CN}$ was added to an acetonitrile solution containing $\mathrm{Mn}\left(4-{ }^{t} \mathrm{BuC}_{6} \mathrm{H}_{4} \mathrm{COO}\right)_{2} \cdot 3 \mathrm{H}_{2} \mathrm{O}$. Almost immediately a pale yellow suspension was formed. After 5 minutes of stirring, the solid was filtered and washed with $\mathrm{CH}_{3} \mathrm{CN}$. Yield: $70 \%$. Tiny single-crystals were obtained from the mother liquor several months after the separation of the previous solid. $\mathrm{C}_{32} \mathrm{H}_{36} \mathrm{MnN}_{2} \mathrm{O}_{5}$ (M.W. $=583.57 \mathrm{~g} \mathrm{~mol}{ }^{-1}$ ). Anal. Calcd (\%): C, 65.86; H, 6.22; N, 4.08. Found (\%): C, 63.63; H, 6.39; N, 4.03. IR ( $\mathrm{cm}^{-1}$ ): 3425 (br), 3067 (w), 2963 (m), 2903 (w), 2868 (w), 1602 (s), 1553 (s), 1491 (w), 1475 (m), 1441 (m), 1401 (s), $1316(\mathrm{w}), 1267$ (w), $1190(\mathrm{w}), 1148(\mathrm{w}), 1106(\mathrm{w}), 1058(\mathrm{w})$, $1017(\mathrm{~m}), 861(\mathrm{~m}), 788(\mathrm{~m}), 769(\mathrm{~m}), 714(\mathrm{~m}), 649(\mathrm{w}), 585(\mathrm{w})$, $543(\mathrm{w}), 559(\mathrm{w}), 414(\mathrm{w})$.

$\left[\mathrm{Mn}_{3}(\mathrm{bpy})_{2}\left(\boldsymbol{\mu}-3-\mathrm{MeOC}_{6} \mathrm{H}_{4} \mathrm{COO}\right)_{6}\right] \quad$ (11). $\mathrm{Mn}(3-$ $\left.\mathrm{MeOC}_{6} \mathrm{H}_{4} \mathrm{COO}\right)_{6} \cdot 2 / 3 \mathrm{EtOH}(0.12 \mathrm{mmol}, 0.045 \mathrm{~g})$ was dissolved in $\mathrm{CH}_{3} \mathrm{CN}(10 \mathrm{~mL})$ and $\mathrm{H}_{2} \mathrm{O}(5 \mathrm{~mL})$. Then, bpy $(0.078 \mathrm{mmol}$, $0.012 \mathrm{~g}$ ) dissolved in $\mathrm{CH}_{3} \mathrm{CN}(10 \mathrm{~mL})$ was added to the previous solution. After 1 month of slow evaporation, yellow crystals were filtered and washed with $\mathrm{CH}_{3} \mathrm{CN}$. Yield: $43 \%$. $\mathrm{C}_{68} \mathrm{H}_{58} \mathrm{Mn}_{3} \mathrm{~N}_{4} \mathrm{O}_{18}$ (M.W. = $1384.02 \mathrm{~g} \mathrm{~mol}^{-1}$ ). Anal. Calcd (\%): C, 59.01; H, 4.22; N, 4.05. Found (\%): C, 58.72; H, 4.22; N, 4.15. IR (cm $\left.{ }^{-1}\right)$ : $3444(\mathrm{br}), 3108(\mathrm{w}), 3001(\mathrm{w}), 2963(\mathrm{w}), 2938(\mathrm{w})$, 2831 (w), 1598 (m), 1565 (s), 1473 (w), 1452 (m), 1400 (s), 1315 (m), 1282 (m), 1239 (s), 1177 (w), 1157 (m), 1108 (w), 1047 (s), $1018(\mathrm{~m}), 902(\mathrm{~m}), 785(\mathrm{~m}), 764(\mathrm{~s}), 684(\mathrm{w}), 670(\mathrm{w})$, $647(\mathrm{w}), 625(\mathrm{w}), 543(\mathrm{w}), 450(\mathrm{w})$. 
$\left[\mathrm{Mn}_{3}(\mathrm{bpy})_{2}\left(\boldsymbol{\mu}-\mathbf{4}-\mathrm{MeOC}_{6} \mathrm{H}_{4} \mathrm{COO}\right)_{6}\right] \quad$ (12). Bpy $(0.50 \mathrm{mmol}$, $0.08 \mathrm{~g})$ dissolved in $\mathrm{EtOH}$ was added to a suspension of $\mathrm{Mn}(4-$ $\left.\mathrm{MeOC}_{6} \mathrm{H}_{4} \mathrm{COO}\right)_{2} \cdot 2 \mathrm{H}_{2} \mathrm{O}(0.75 \mathrm{mmol}, 0.29 \mathrm{~g})$ in EtOH. The resulting pale yellow mixture was stirred for 10 minutes. Then, the solid was separated by filtration and washed with $\mathrm{Et}_{2} \mathrm{O}$. Yield: $76 \%$. X-ray suitable single-crystals were obtained by slow diffusion of a solution of bpy $(0.008 \mathrm{~g})$ in $\mathrm{CH}_{3} \mathrm{CN}(8 \mathrm{~mL})$ to another one containing $\mathrm{Mn}\left(4-\mathrm{MeOC}_{6} \mathrm{H}_{4} \mathrm{COO}\right)_{2} \cdot 2 \mathrm{H}_{2} \mathrm{O}(0.03 \mathrm{~g})$ in $\mathrm{CH}_{3} \mathrm{CN}(8 \mathrm{~mL})$ after 6 months. $\mathrm{C}_{68} \mathrm{H}_{58} \mathrm{Mn}_{3} \mathrm{~N}_{4} \mathrm{O}_{18}$ (M.W. = $1384.02 \mathrm{~g} \mathrm{~mol}^{-1}$ ). Anal. Calcd (\%): C, 59.01; H, 4.22; N, 4.05. Found (\%): C, 56.65; H, 4.05; N, 4.05. IR $\left(\mathrm{cm}^{-1}\right): 3433(\mathrm{br})$, 3081 (w), 2953 (w), 2835 (w), 1606 (s), 1557 (s), 1488 (w), 1471 (m), $1440(\mathrm{~m}), 1390(\mathrm{~s}), 1310(\mathrm{~m}), 1256(\mathrm{~s}), 1168(\mathrm{~s}), 1140(\mathrm{~m})$, $1103(\mathrm{w}), 1029(\mathrm{w}), 851(\mathrm{~m}), 785(\mathrm{~s}), 763(\mathrm{~m}), 737(\mathrm{w}), 699(\mathrm{~m})$, $615(\mathrm{~m}), 569(\mathrm{w}), 509(\mathrm{w}), 414(\mathrm{~m})$.

$\left[\mathrm{Mn}_{3}\left(\mu-3-\mathrm{MeOC}_{6} \mathrm{H}_{4} \mathrm{COO}\right)_{6}(\text { phen })_{2}\right] \quad$ (13). $\quad \mathrm{Mn}(3-$ $\left.\mathrm{MeOC}_{6} \mathrm{H}_{4} \mathrm{COO}\right)_{6} \cdot 2 / 3 \mathrm{EtOH}(0.12 \mathrm{mmol}, 0.045 \mathrm{~g})$ was dissolved in EtOH $(15 \mathrm{~mL})$ and $\mathrm{H}_{2} \mathrm{O}(5 \mathrm{~mL})$. Then, phen $(0.078 \mathrm{mmol}$, $0.015 \mathrm{~g})$ dissolved in EtOH $(10 \mathrm{~mL})$ was added to the previous solution. After 1 or 2 months of slow evaporation, yellow crystals were filtered and washed with $\mathrm{CH}_{3} \mathrm{CN}$. Yield: $46 \%$. $\mathrm{C}_{72} \mathrm{H}_{58} \mathrm{Mn}_{3} \mathrm{~N}_{4} \mathrm{O}_{18}$ (M.W. $=1432.06 \mathrm{~g} \mathrm{~mol}^{-1}$ ). Anal. Calcd (\%): C, 60.67; H, 4.08; N, 3.91. Found (\%): C, 58.98; H, 4.18; N, 4.05. IR $\left(\mathrm{cm}^{-1}\right)$ : $3433(\mathrm{br}), 3068(\mathrm{w}), 2999(\mathrm{w}), 2929(\mathrm{w}), 2828(\mathrm{w})$, $1600(\mathrm{~m}), 1568(\mathrm{~s}), 1540(\mathrm{~s}), 1516(\mathrm{~m}), 1451$ (m), 1395 (s), 1314 (w), $1282(\mathrm{w}), 1242(\mathrm{~m}), 1106(\mathrm{w}), 1042(\mathrm{~m}), 904(\mathrm{w}), 849(\mathrm{~m})$, $764(\mathrm{~m}), 727(\mathrm{~m}), 669(\mathrm{w}), 637(\mathrm{w}), 533(\mathrm{w})$.

$\left[\mathrm{Mn}_{3}\left(\boldsymbol{\mu}-4-\mathrm{MeOC}_{6} \mathrm{H}_{4} \mathrm{COO}\right)_{6}(\text { phen })_{2}\right] \cdot$ EtOH

(14). $\quad \operatorname{Mn}(4-$ $\left.\mathrm{MeOC}_{6} \mathrm{H}_{4} \mathrm{COO}\right)_{2} \cdot 2 \mathrm{H}_{2} \mathrm{O}(0.12 \mathrm{mmol}, 0.42 \mathrm{~g})$ was dissolved in a mixture of EtOH $(15 \mathrm{~mL})$ and $\mathrm{H}_{2} \mathrm{O}(5 \mathrm{~mL})$. Then, phen $(0.078 \mathrm{mmol}, 0.015 \mathrm{~g})$ dissolved in EtOH $(10 \mathrm{~mL})$ was added. The resulting pale yellow solution was stirred for 10 minutes and filtered to separate any possible impurity. After two months of slow evaporation, yellow crystals were filtered and washed with EtOH. Yield: $44 \% . \quad \mathrm{C}_{72} \mathrm{H}_{58} \mathrm{Mn}_{3} \mathrm{~N}_{4} \mathrm{O}_{18} \cdot \mathrm{EtOH}$ (M.W. = $1478.13 \mathrm{~g} \mathrm{~mol}^{-1}$ ). Anal. Calcd (\%): C, 60.13; H, 4.36; $\mathrm{N}, 3.79$. Found (\%): C, 60.12; H, 4.46; N, 3.87. IR $\left(\mathrm{cm}^{-1}\right): 3420$ (br), 3064 (w), 2995 (w), 2957 (w), 2929 (w), 2833 (m), 1607 (s), 1559 (s), 1510 (s), 1398 (s), 1312 (w), 1255 (s), 1169 (m), $1144(\mathrm{w}), 1101(\mathrm{w}), 1034(\mathrm{~m}), 852(\mathrm{~m}), 783(\mathrm{~s}), 731(\mathrm{~m}), 700(\mathrm{w})$, $616(\mathrm{~s}), 568(\mathrm{w}), 510(\mathrm{w})$.

\section{Physical characterisation}

$\mathrm{C}, \mathrm{H}$ and $\mathrm{N}$ analyses were carried out by the "Centres Científics i Tecnològics" of the Universitat de Barcelona. Infrared spectra were recorded on $\mathrm{KBr}$ pellets in the $4000-400 \mathrm{~cm}^{-1}$ range with a Thermo Nicolet Avatar 330 FTIR spectrometer. Magnetic measurements were performed on microcrystalline samples in a Quantum Design MPMS XL5 SQUID Magnetometer at the "Unitat de Mesures Magnètiques" (Universitat de Barcelona). Magnetic susceptibility was measured between 2 and $300 \mathrm{~K}$ with a magnetic field of 0.02 T. Magnetisation measurements were performed at $2 \mathrm{~K}$ from 0 to 5.0 T. Pascal's constant was used to estimate the diamagnetic corrections for the compound. The fit of the experimental magnetic data was performed by minimizing the func- tion $R=\sum\left[\left(\chi_{\mathrm{M}} T\right)_{\exp }-\left(\chi_{\mathrm{M}} T\right)_{\text {calcd }}\right]^{2} / \sum\left[\left(\chi_{\mathrm{M}} T\right)_{\exp }\right]^{2}$. Solid-state EPR spectra were recorded at X-band $(9.4 \mathrm{GHz})$ frequency using a Bruker ESP-300E spectrometer from room temperature to $4 \mathrm{~K}$ at the "Unitat de Mesures Magnètiques" (Universitat de Barcelona).

\section{Single-crystal X-ray crystallography}

The data collection for compounds 2, 6, 7, 8 (at 90-100 K), 5, and 9 (at $302 \mathrm{~K}$ ) was performed on a Bruker Apex-II diffractometer, whereas for 1,3 , and 12 , it was performed at room temperature on a MAR345 diffractometer, both equipped with graphite monochromatic Mo K $\alpha$ radiation $(\lambda=0.71073 \AA)$. Unit-cell parameters were determined using $230-9972$ reflections and refined by the least-squares method. 6090- 127139 reflections were collected using the $\Phi$ - and $\omega$-scan (Bruker Apex-II) or $\Phi$-scan (MAR345) method. Data were corrected for absorption effects using multi-scan $(2,6,8,7,5$, and 9) or empirical $\left(\mathbf{1}, 3\right.$, and 12) methods (SADABS) ${ }^{28}$ Tables containing crystallographic data collection and structure refinement details are summarised in the ESI (Tables S1-S3†).

The structures were solved by direct methods and refined by full-matrix least-squares using SHELXL-97. ${ }^{29}$ Non-hydrogen atoms were refined anisotropically, whereas hydrogen atoms were computed and refined with isotropic thermal parameters riding on their respective carbon or oxygen atoms. The crystal structures of compounds $1,3,5$, and 12 were isotropically refined without any complication, but they showed high $R_{1}$ and $\mathrm{w} R_{2}$ values and, in some cases, the presence of spurious peaks very close to other atoms. These peaks not only complicate the refinement of the anisotropic displacements but also altered the results. Therefore, the reflections showing high standard deviations were removed from the $H K L$ files of $\mathbf{1}, \mathbf{3}, \mathbf{5}$, and 12, enabling us to better refine the structures and providing much better results. Even though some reflections were removed, the relationship between parameters to refine and reflections were more than enough to refine the structure in an appropriate way.

Compounds 1, 3, 5, and 6 crystallise in the triclinic space group $P \overline{1}$. The asymmetric unit consists of half a $\left[\left\{\mathrm{Mn}(\mathrm{NN})_{2}\right\}_{2}\left(\mu-n-\mathrm{RC}_{6} \mathrm{H}_{4} \mathrm{COO}\right)_{2}\right]^{2+}$ complex and one $\mathrm{ClO}_{4}{ }^{-}$ anion. The other half of the complex is generated by an inversion centre. Around 400 parameters were refined in the final cycle of refinement on $F^{2}$ using no more than 15 restraints.

Compound 2 crystallises in the monoclinic space group $P 21 / c$. The asymmetric unit consists of half a $\left[\left\{\mathrm{Mn}(\mathrm{bpy})_{2}\right\}_{2}(\mu-3-\right.$ $\left.\left.\mathrm{MeOC}_{6} \mathrm{H}_{4} \mathrm{COO}\right)_{2}\right]^{2+}$ complex and a $\mathrm{ClO}_{4}{ }^{-}$anion. The other half of the complex is generated by an inversion centre. A total of 370 parameters were refined in the final cycle of refinement on $F^{2}$ without using any restraint.

Compound 7 crystallises in the monoclinic space group $C 2 / m$. The asymmetric unit consists of a fourth part of a $\left[\left\{\mathrm{Mn}(\mathrm{phen})_{2}\right\}_{2}\left(\mu-4-\mathrm{MeOC}_{6} \mathrm{H}_{4} \mathrm{COO}\right)_{2}\right]^{2+}$ complex and half a $\mathrm{ClO}_{4}{ }^{-}$anion. The rest of the complex is generated by an inversion centre and a mirror plane. A total of 239 parameters were refined in the final cycle of refinement on $F^{2}$ using 36 restraints. 
Compound $\mathbf{8}$ crystallises in the triclinic space group $P \overline{1}$. The asymmetric unit consists of a $\left[\mathrm{Mn}\left(\mathrm{H}_{2} \mathrm{O}\right)\left(3-\mathrm{MeOC}_{6} \mathrm{H}_{4} \mathrm{COO}\right)\right.$ (phen) $\left.)_{2}\right]^{+}$complex and a $\mathrm{ClO}_{4}{ }^{-}$anion. A total of 424 parameters were refined in the final cycle of refinement on $F^{2}$ without using any restraint.

Compound 9 crystallises in the monoclinic space group $C c$. The asymmetric unit consists of four slightly different complexes with the formula $\left[\mathrm{Mn}\left(\mathrm{H}_{2} \mathrm{O}\right)_{2}\left(2-\mathrm{MeOC}_{6} \mathrm{H}_{4} \mathrm{COO}\right)_{2}(\right.$ phen $\left.)\right]$. The $\mathrm{H}$ atoms of the water ligands were fixed in logical positions considering the plausible $\mathrm{H}$ bonds, with isotropic thermal parameters riding on their respective $\mathrm{O}$ atoms. A total of 448 parameters were refined in the final cycle of refinement on $F^{2}$ without using any restraint.

Single crystals of the mononuclear compound $\mathbf{1 0}$ were isolated and mounted on a diffractometer. However, the crystals were very thin, so they did not provide good diffraction frames and the structure could not be determined.

Compound 12 crystallises in the triclinic space group $P \overline{1}$. The asymmetric unit consists of half a $\left[\mathrm{Mn}_{3}(\mathrm{bpy})_{2}(\mu-4-\right.$ $\left.\left.\mathrm{MeOC}_{6} \mathrm{H}_{4} \mathrm{COO}\right)_{6}\right]$ complex. The rest of the complex is generated by an inversion centre. A total of 448 parameters were refined in the final cycle of refinement on $F^{2}$ without using any restraint.

\section{Results and discussion}

\section{Synthesis}

The reaction between $\mathrm{Mn}^{\mathrm{II}}$ salts, carboxylate ligands, and nitrogen-based ligands (NN) is well described in the literature. ${ }^{26,27,30-42}$ As a function of the $\mathrm{Mn}^{\mathrm{II}}$ : carboxylate $\mathrm{NN}$ ratio, the solvent, the presence or absence of certain counter-anions, and the degree of deprotonation of some ligands, different kinds of compounds with diverse nuclearity can be obtained consisting of ionic or neutral complexes. Moreover, carboxylate ligands can display a wide number of coordination modes.

In this work, the reaction between the corresponding $\mathrm{Mn}^{\mathrm{II}}$ carboxylate, $\mathrm{Mn}\left(n-\mathrm{RC}_{6} \mathrm{H}_{4} \mathrm{COO}\right)_{2}(n-\mathrm{R}=2-\mathrm{MeO}, 3-\mathrm{MeO}, 4-\mathrm{MeO}$, and $4{ }^{t} \mathrm{Bu}$ ), and a bidentate nitrogen-based ligand (NN), 2,2'bipyridine (bpy) or 1,10-phenantroline (phen), led to the formation of seven ionic dinuclear (1-7), three mononuclear (ionic, 8, or neutral, 9 and 10), and four neutral trinuclear (11-14) compounds. The kinds of compounds obtained for each couple of ligands are summarised in Table 1. Fig. 1

Table 1 List of compounds obtained for each couple of ligands

\begin{tabular}{lllll}
\hline $\mathrm{R}$ & $\mathrm{NN}$ & {$\left[\mathrm{Mn}_{2}\right]$ ionic } & {$[\mathrm{Mn}]$} & {$\left[\mathrm{Mn}_{3}\right]$} \\
\hline $2-\mathrm{MeO}$ & bpy & $\mathbf{1}\left(\mu_{1,3}\right)^{a}$ & - & - \\
$3-\mathrm{MeO}$ & bpy & $\mathbf{2}\left(\mu_{1,3}\right)^{a}$ & - & $\mathbf{1 1}^{a}$ \\
$4-\mathrm{MeO}$ & bpy & $\mathbf{3}\left(\mu_{1,3}\right)^{a}$ & - & $\mathbf{1 2}$ \\
$4-{ }^{t} \mathrm{Bu}$ & bpy & - & $\mathbf{1 0}$ (neutral) $^{-}$ & - \\
$2-\mathrm{MeO}$ & phen & $\mathbf{4}\left(\mu_{1,3}\right)$ & $\mathbf{9}$ (neutral) $^{a}$ & - \\
$3-\mathrm{MeO}$ & phen & $\mathbf{6}\left(\mu_{1,1}\right)^{a}$ & $\mathbf{8}$ (ionic $^{a}$ & $\mathbf{1 3}$ \\
$4-\mathrm{MeO}$ & phen & $7\left(\mu_{1,1}\right)^{a}$ & - & $\mathbf{1 4}$ \\
$4-{ }^{t} \mathrm{Bu}$ & phen & $\mathbf{5}\left(\mu_{1,3}\right)^{a}$ & - & -
\end{tabular}

${ }^{a}$ Compounds from which the crystal structures have been determined.

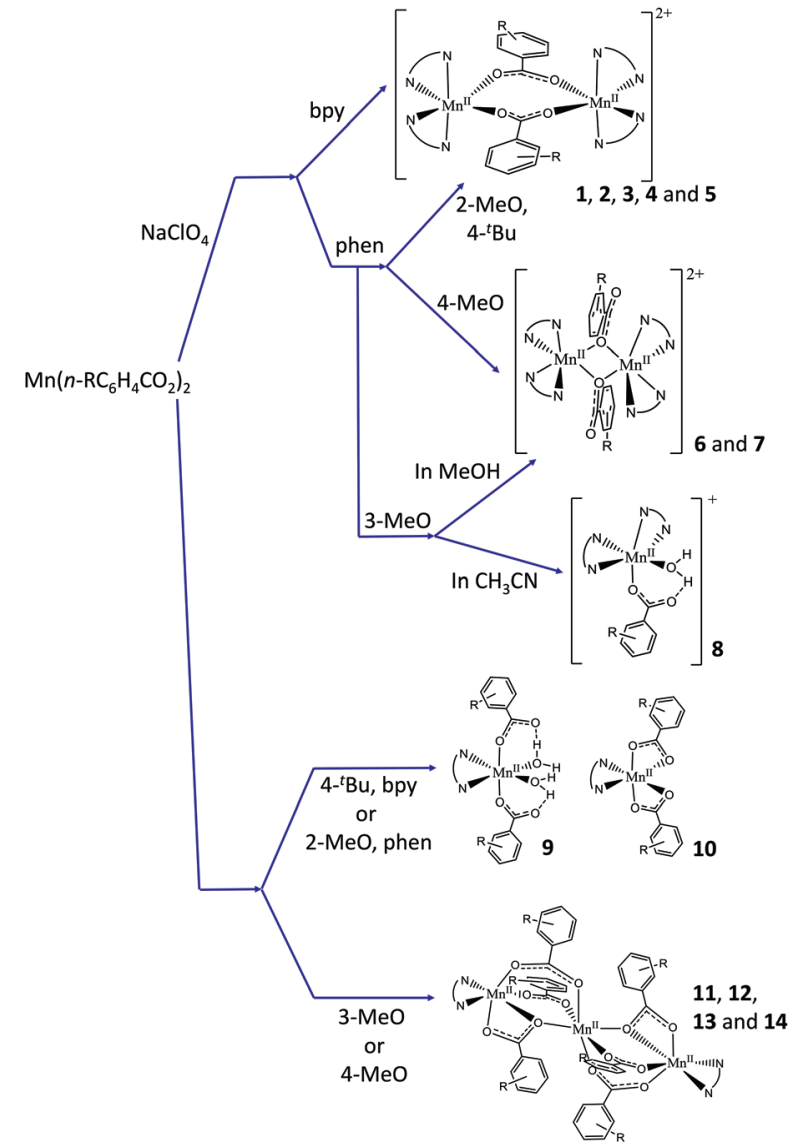

Fig. 1 Diagram showing compounds formed depending on the reagents, stoichiometry, and the solvent.

shows a concise diagram of the reactions and the obtained compounds, depending on the presence or absence of $\mathrm{ClO}_{4}{ }^{-}$ ions and the solvent used when these were determining factors.

When $\mathrm{NaClO}_{4}$ was added besides the $\mathrm{Mn}^{\mathrm{II}}$ carboxylate and the $\mathrm{NN}$ ligand, ionic dinuclear compounds with the formula $\left[\left\{\mathrm{Mn}(\mathrm{NN})_{2}\right\}_{2}\left(\mu-n-\mathrm{RC}_{6} \mathrm{H}_{4} \mathrm{COO}\right)_{2}\right]\left(\mathrm{ClO}_{4}\right)_{2}(\mathbf{1}-3$, with $\mathrm{NN}=$ bpy; 4-7, with $\mathrm{NN}=$ phen) were obtained. It was not possible to obtain this kind of compound for $n-\mathrm{R}=4{ }^{t}{ }^{t} \mathrm{Bu}$ and $\mathrm{NN}=$ bpy. In most cases, the use of $\mathrm{CH}_{3} \mathrm{CN}$ or EtOH led to the formation of the same compound. However, for $n-\mathrm{R}=3-\mathrm{MeO}$ and $\mathrm{NN}=$ phen, a mononuclear compound with the formula $\left[\mathrm{Mn}\left(\mathrm{H}_{2} \mathrm{O}\right)\right.$ $\left.\left(3-\mathrm{MeOC}_{6} \mathrm{H}_{4} \mathrm{COO}\right)(\text { phen })_{2}\right]\left(\mathrm{ClO}_{4}\right)(8)$ was obtained in these solvents in the presence of a small amount of water. The formation of the dinuclear compound 6 (3-MeO/phen) was only attained in $\mathrm{MeOH}$.

As reported previously, when no perchlorate salt is added, neutral compounds of different nuclearities could be obtained as a function of the $\mathrm{Mn}: \mathrm{NN}$ ratio $(3: 2$ or $1: 1)$ and/or solvent. ${ }^{27,30}$ With the manganese carboxylates used in this work, the $\mathrm{Mn}: \mathrm{NN}$ ratio and the solvent $\left(\mathrm{CH}_{3} \mathrm{CN}\right.$ or EtOH) made no difference in the type of product that was formed, but they did for the conditions of crystallisation (time, crystallinity, etc.) and/or the purity of the sample. For instance, nice 
yellow crystals of $\mathbf{9}$ were obtained in $\mathrm{EtOH}$, while the sample contaminated with some brown product precipitated in $\mathrm{CH}_{3} \mathrm{CN}$. All attempts to obtain some neutral compounds with $n-\mathrm{R}=2-\mathrm{MeO}$ and $\mathrm{NN}=$ bpy were unsuccessful; nevertheless, when $\mathrm{NN}=$ phen, the mononuclear compound $\mathbf{9}$ was obtained. Similarly, for $n$ - $\mathrm{R}=4-{ }^{t} \mathrm{Bu}$ and $\mathrm{NN}=\mathrm{bpy}$, a mononuclear compound was obtained (10), while we did not succeed in establishing any reproducible synthesis using phen. The formation of trinuclear compounds was attained when $n-\mathrm{R}=3-\mathrm{MeO}$ and 4-MeO with both NN ligands.

The presence of water in the reaction medium was required in nearly all cases, since it assists the dissolution of the $\mathrm{Mn}^{\mathrm{II}}$ carboxylates. Nevertheless, $\mathrm{H}_{2} \mathrm{O}$ also guaranteed the formation of the dinuclear compounds $\mathbf{3}$ and $\mathbf{5}$ because it prevented the fast precipitation of the corresponding neutral compounds, observed after several minutes of stirring when no additional $\mathrm{H}_{2} \mathrm{O}$ was added.

Regarding the dinuclear compounds, two different coordination modes of the carboxylate ligands can be found, even though the synthetic method is the same. Fortunately, these coordination modes can be easily differentiated with the 1620-1300 $\mathrm{cm}^{-1}$ window of the IR spectra of these compounds. Although the nitrogen-based ligands (bpy and phen) show some bands in this region, it is possible to identify the two characteristic bands of the carboxylate groups, assigned to the asymmetric $\left(\nu_{\mathrm{a}}\right)$ and symmetric $\left(\nu_{\mathrm{s}}\right)$ vibrations. Values of $\Delta \nu=\nu_{\mathrm{a}}(\mathrm{COO})-\nu_{\mathrm{s}}(\mathrm{COO})<200 \mathrm{~cm}^{-1}$ indicate that the carboxylate ligands show a $\mu_{1,3}$-coordination mode, whereas values of $\Delta \nu>200 \mathrm{~cm}^{-1}$ are indicative of a $\mu_{1,1}$-coordination mode. ${ }^{26,43}$ For compounds $\mathbf{1 - 5}$, the bands assigned to the carboxylate ligands arise at $\sim 1550$ and $\sim 1390 \mathrm{~cm}^{-1}$, with $\Delta \nu \approx 160 \mathrm{~cm}^{-1}$, consistent with a $\mu_{1,3}$-coordination mode. In contrast, 6 and 7 show two bands at $\sim 1570$ and $\sim 1310 \mathrm{~cm}^{-1}$ (with $\Delta \nu \approx$ $260 \mathrm{~cm}^{-1}$ ), consistent with a $\mu_{1,1}$-coordination mode.

The reason why one type of bridge is preferentially formed is very difficult to rationalise. As explained by Gómez et al., two factors could contribute to this different behaviour: the steric and the electronic effects. In the referred work, only compounds containing phen and the $\mathrm{R}$ group in meta or para position show a $\mu_{1,1}$-coordination mode. ${ }^{26}$ Compounds with $\mathrm{R}=$ $\mathrm{MeO}$ follow the same tendency: while compounds 6 and 7, with the respective $n-\mathrm{R}=3-\mathrm{MeO}$ and $4-\mathrm{MeO}$, have $\mu_{1,1}$-brigdes, compound 4, with $n-\mathrm{R}=2-\mathrm{MeO}$, exhibits a $\mu_{1,3}$-coordination mode. However, compound $5\left(n-\mathrm{R}=4-{ }^{t} \mathrm{Bu}\right)$, whose carboxylate shows a $\mu_{1,3}$-coordination mode, does not follow the expected trend. The cause of this variation may lie in the presence of the highly voluminous ${ }^{t} \mathrm{Bu}$ group that, in spite of being in para position, can be the source of steric hindrance. Indeed, the formation of the $\mu_{1,1}$-brigde shortens the $\mathrm{Mn} \cdots \mathrm{Mn}$ distance from $\sim 4.65$ (for a $\mu_{1,3}$-brigde) to $\sim 3.46 \AA$, also setting the facing phen ligands closer (see below).

\section{Description of structures}

Dinuclear compounds with $\mu_{1,3}-n-\mathrm{RC}_{6} \mathrm{H}_{4} \mathrm{COO}^{-}$bridges (1, 2, 3 , and 5). Compounds 1, 2, 3, and 5 show an analogous structure, consisting of a cationic complex with the formula
$\left[\left\{\mathrm{Mn}(\mathrm{NN})_{2}\right\}_{2}\left(\mu-n-\mathrm{RC}_{6} \mathrm{H}_{4} \mathrm{COO}\right)_{2}\right]^{2+}$ and two perchlorate anions. To exemplify, Fig. 2 shows the crystal structure of the cationic complex of one of them (3). Those of compounds 1, 2, and 5 are found in the ESI (Fig. S1 $\dagger$ ). Selected interatomic distances and angles are listed in Table $\mathrm{S} 4 . \dagger$

The two $\mathrm{Mn}^{\mathrm{II}}$ ions are bridged by two $\mu_{1,3}-n-\mathrm{RC}_{6} \mathrm{H}_{4} \mathrm{COO}^{-}$ ligands in syn-anti mode, with $\mathrm{Mn} \cdots \mathrm{Mn}$ distances ranging from 4.54 to $4.75 \AA$. The hexacoordination of each $\mathrm{Mn}$ ion is completed by two bpy (1, 2 and $\mathbf{3})$ or phen (5) ligands. The $\mathrm{Mn}-\mathrm{O}$ and $\mathrm{Mn}-\mathrm{N}$ distances are in the ranges $2.09-2.14 \AA$ and 2.26-2.36 $\AA$, respectively, leading to distorted octahedral environments around the $\mathrm{Mn}^{\mathrm{II}}$ ions. All these structural parameters are in agreement with those reported for analogous compounds. ${ }^{26,30-34,44,45}$

Dinuclear compounds with $\mu_{1,1}-n-\mathrm{RC}_{6} \mathrm{H}_{4} \mathrm{COO}^{-}$bridges (6 and 7). Compounds 6 and 7, with the formula $\left[\left\{\mathrm{Mn}(\text { phen })_{2}\right\}_{2}\left(\mu-n-\mathrm{MeOC}_{6} \mathrm{H}_{4} \mathrm{COO}\right)_{2}\right]\left(\mathrm{ClO}_{4}\right)_{2}$, display a very similar structure. Fig. 3 shows the crystal structure of the cationic

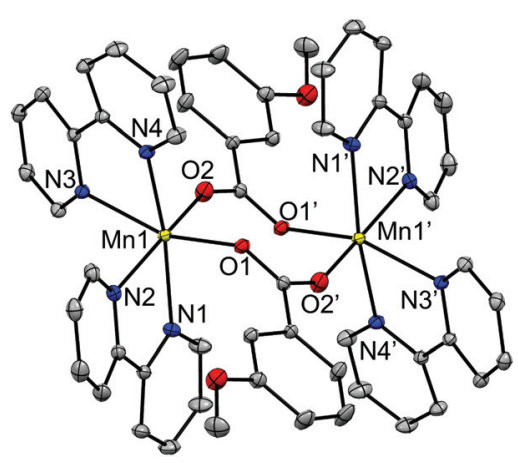

Fig. 2 Crystal structures of the cationic complexes of compound 2, showing the anisotropic displacements as ellipsoids at $50 \%$ probability. Hydrogen atoms are omitted for clarity.

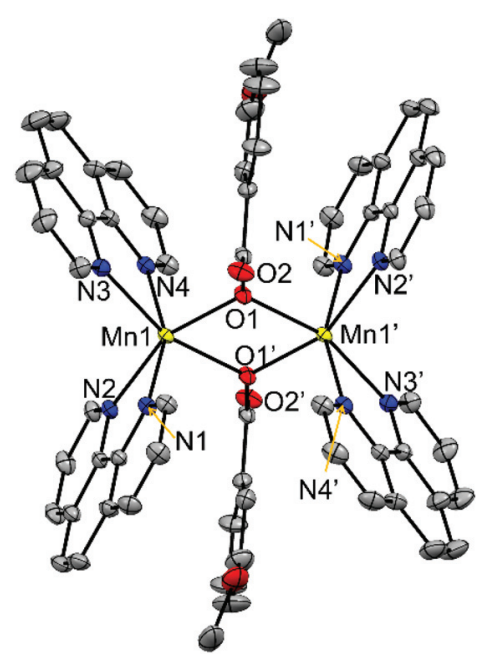

Fig. 3 Crystal structures of the cationic complexes of compounds 6 , showing the anisotropic displacements as ellipsoids at $50 \%$ probability. Hydrogen atoms are omitted for clarity. 
complex of compound 6. That of 7 may be found in the ESI (Fig. S2 $\dagger$ ). Selected interatomic distances and angles are listed in Table S5. $\dagger$

The two $\mathrm{Mn}^{\mathrm{II}}$ ions are linked through two $\mu_{1,1}-n$ $\mathrm{RC}_{6} \mathrm{H}_{4} \mathrm{COO}^{-}$bridges, with $\mathrm{Mn} \cdots \mathrm{Mn}$ distances of $\sim 3.45 \AA$ A. Two phen ligands are linked to each $\mathrm{Mn}^{\mathrm{II}}$ ion, leading to distorted octahedral geometry. The $\mathrm{Mn}-\mathrm{O}$ distances are in the range 2.16-2.18 $\AA$ while the $\mathrm{Mn}-\mathrm{N}$ are $2.26 \AA$. The $\mathrm{Mn}_{2} \mathrm{O}_{2}$ ring is planar, and the $\mathrm{Mn}-\mathrm{O}-\mathrm{Mn}$ ring is close to $105^{\circ}$. The structural parameters for compounds 6 and 7 are in agreement with those reported for analogous compounds with the $\left[\mathrm{Mn}_{2}\left(\mu_{1,1}-\mathrm{R}^{\prime}\right.\right.$ CCO $\left.)_{2}\right]^{2+}$ core. $^{26,35,36,46}$

In these compounds the phenyl ring and the carboxylate groups of the benzoate derivative bridge are almost coplanar and are perpendicular to the $\mathrm{Mn}_{2} \mathrm{O}_{2}$ ring. As may be seen comparing the structures of compounds containing $\mu_{1,3^{-}}$and $\mu_{1,1^{-}}$ brigdes (Fig. 2 and 3, respectively), the shorter Mn $\cdots$ Mn distance in the latter keeps the $\mathrm{NN}$ ligands closer to the aromatic ring of the carboxylate bridge and, consequently, this aromatic ring, which is found between two phen ligands, is forced to twist and become placed almost parallel to these ligands. For compounds 6 and 7, the R group (3-MeO and 4-MeO, respectively) remains in the same plane as the phenyl ring, so their presence does not disturb the formation of the $\mu_{1,1}$-bridges. On the other hand, the bulky ${ }^{t} \mathrm{Bu}$ group has two methyl groups that stand out from the plane of the phenyl group, being able to cause steric hindrance. Hence, the formation of a dinuclear compound with $\mu_{1,1}-4{ }^{t} \mathrm{BuC}_{6} \mathrm{H}_{4} \mathrm{COO}^{-}$bridges could be tentatively considered improvable. The obtained dinuclear compound with this ligand shows $\mu_{1,3}$-bridges (5).

Mononuclear compounds (8-10). Fig. 4 shows the crystal structure of the two mononuclear compounds with 3-MeO (8) and 2-MeO (9) benzoate derivatives. Selected structural parameters are listed in Table S6. $\dagger$

The structure of compound 8 consists of a cationic complex with the formula $\left[\mathrm{Mn}\left(\mathrm{H}_{2} \mathrm{O}\right)\left(3-\mathrm{MeOC}_{6} \mathrm{H}_{4} \mathrm{COO}\right)(\mathrm{phen})_{2}\right]^{+}$and a perchlorate anion. The carboxylate ligand is coordinated in a
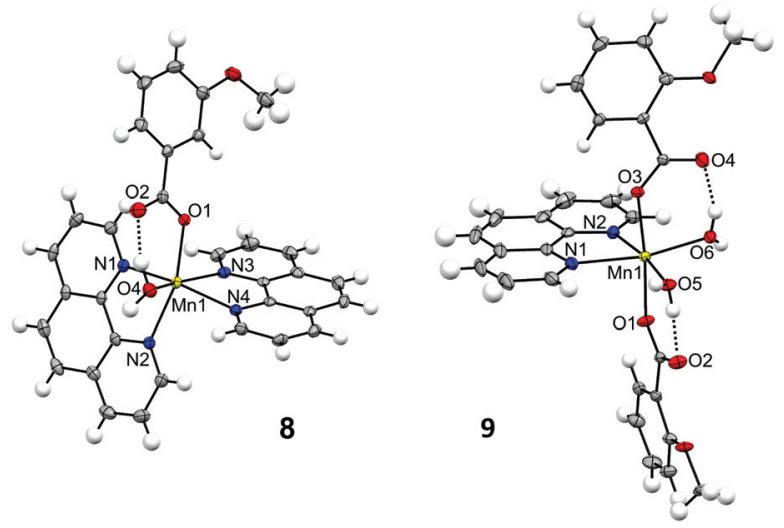

Fig. 4 Crystal structures for the cationic complex of 8 and for one of the subunits of compound 9, showing the anisotropic displacements as ellipsoids at $50 \%$ probability. monodentate mode, with $\mathrm{Mn}-\mathrm{O}$ distances of $\sim 2.15 \AA$ A. There are hydrogen bonds between the $\mathrm{H}_{2} \mathrm{O}$ molecule and the hanging oxygen atom of the carboxylate ligand $(\mathrm{O} 2)$. The hexacoordination of the $\mathrm{Mn}^{\mathrm{II}}$ ion is completed by two phen ligands, with $\mathrm{Mn}-\mathrm{N}$ distances of $\sim 2.26 \AA$. The structure of compound 9 comprises four neutral complexes with the formula $\left[\mathrm{Mn}\left(\mathrm{H}_{2} \mathrm{O}\right)_{2}\left(2-\mathrm{MeOC}_{6} \mathrm{H}_{4} \mathrm{COO}\right)_{2}(\right.$ phen $\left.)\right]$ with very similar structural parameters (Fig. S3 and Table S7†). Fig. 4 and Table S6† only concern the structure of one of these complexes. In this compound, the two carboxylate ligands are coordinated in monodentate mode. Each hanging oxygen atom of these ligands is interacting with one of the $\mathrm{H}_{2} \mathrm{O}$ molecules through hydrogen bonds. The hexacoordination of the $\mathrm{Mn}^{\mathrm{II}}$ ion is completed by one phen ligand, with $\mathrm{Mn}-\mathrm{N}$ distances of $\sim 2.28 \AA$ A. The $\mathrm{Mn}^{\mathrm{II}}$ ions in these compounds show a distorted octahedral geometry.

Crystals of compound $\mathbf{1 0}$ were poorly diffracting and its crystal structure could not be refined. However, some atoms could be assigned to several Q peaks. Apparently, the structure of this compound consists of a neutral complex with the formula $\left[\mathrm{Mn}(\mathrm{bpy})\left(4-{ }^{t} \mathrm{BuC}_{6} \mathrm{H}_{4} \mathrm{COO}\right)_{2}\right]$, where the carboxylate ligands are coordinated in bidentate mode.

Trinuclear $\left[\mathrm{Mn}_{3}(\mathrm{bpy})_{2}\left(\mu-4-\mathrm{MeOC}_{6} \mathrm{H}_{4} \mathrm{COO}\right)_{6}\right]$ compound (12). The structure of compound $\mathbf{1 2}$ is shown in Fig. 5. Selected interatomic distances and angles are listed in Table S8. $\dagger$

The structure of this compound consists of three $\mathrm{Mn}^{\mathrm{II}}$ ions in a linear array, where the central $\mathrm{Mn}$ ion is located at a crystallographic inversion centre. This central ion (Mn2) is coordinated by six oxygen atoms of six 4-methoxybenzoate ligands and is linked to each terminal Mn ion (Mn1) through three 4-methoxybenzoate ligands, with $\mathrm{Mn} \cdots \mathrm{Mn}$ distances of $\sim 3.60 \AA$. While two of these ligands link the Mn ions with both oxygen atoms $\left(\mu_{1,3}\right)$ in a syn-syn mode, the third one links them through just one oxygen atom $\left(\mu_{1,1}\right)$. The Mn-O distances range from 2.15 to $2.25 \AA$. The other oxygen atom $(\mathrm{O} 2)$ of this latter ligand is weakly bonded to the terminal $\mathrm{Mn}$ ion, with

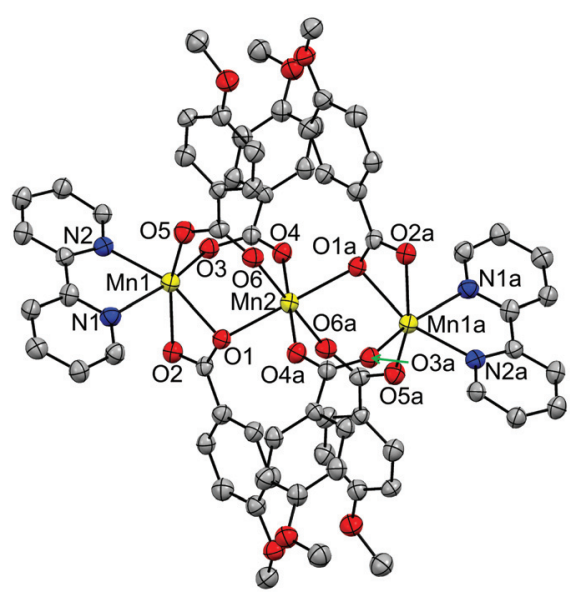

Fig. 5 Crystal structure of compound 12, showing the anisotropic displacements as ellipsoids at $50 \%$ probability. Hydrogen atoms are omitted for clarity. 
Mn-O distances of $2.33 \AA$. The hexacoordination of the terminal ions is completed by a phen ligand, with $\mathrm{Mn}-\mathrm{N}$ distances of $\sim 2.27 \AA$. These structural parameters are in agreement with those reported for analogous compounds. ${ }^{27,30,37-42}$

The terminal Mn ions show a substantial elongation in the direction of the $\mu_{1,1}$ bridge. The central ion, in spite of having angles of $180^{\circ}$ between facing bonds, displays a certain elongation in the direction of the $\mu_{1,1}$ bridge.

\section{Magnetic properties}

Magnetic susceptibility data were recorded for all polynuclear compounds (1-7 and 11-14) from room temperature to $2 \mathrm{~K}$. Magnetisation measurements were performed at $2 \mathrm{~K}$ from 0 to $5.0 \mathrm{~T}$ for the compounds having $S \neq 0$ ground states $(6,7$ and 11-14).

Dinuclear $\left[\left\{\mathrm{Mn}(\mathrm{NN})_{2}\right\}_{2}\left(\boldsymbol{\mu}-\boldsymbol{n}-\mathrm{RC}_{6} \mathrm{H}_{4} \mathrm{COO}\right)_{2}\right]\left(\mathrm{ClO}_{4}\right)_{2}$ compounds (1-7). $\chi_{\mathrm{M}} T$ versus $T$ plots for the dinuclear compounds are represented in Fig. 6 and $S 4 . \dagger$

$\chi_{\mathrm{M}} T$ values at room temperature are close to the value expected for two uncoupled $\mathrm{Mn}^{\mathrm{II}}$ ions. Two different behaviours may be found: (a) for compounds with $\mu_{1,3}$-bridges (1-5), $\chi_{\mathrm{M}} T$ values decrease as the temperature falls, indicative
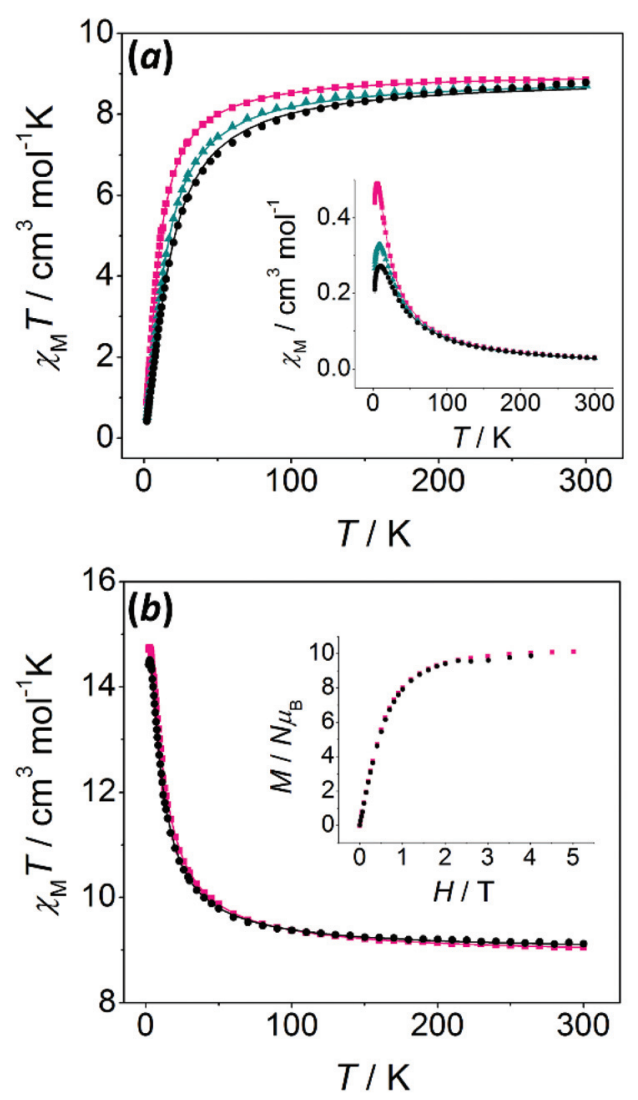

Fig. 6 (a) $\chi_{M} T$ versus $T$ and $\chi_{M}$ versus $T$ (inset) plots for compounds 1 (black circles), 2 (dark cyan triangles), and 3 (pink squares); (b) $\chi_{\mathrm{M}} T$ versus $T$ and $M / N \mu_{\beta}$ versus $H$ plots (inset) for compounds 6 (black circles) and 7 (pink squares). The solid lines correspond to the best fit of the experimental data. of an antiferromagnetic behaviour; (b) for compounds with $\mu_{1,1}$-bridges (6 and 7), $\chi_{\mathrm{M}} T$ values increase as the temperature falls, indicative of a ferromagnetic behaviour. For these compounds, the $S=5$ ground state is confirmed by the field dependence of the magnetisation at $2 \mathrm{~K}$ (inset of Fig. 6b), which shows $M / N \mu_{\beta}$ values consistent with 10 unpaired electrons.

$\chi_{\mathrm{M}} T$ versus $T$ plots were fitted using the PHI program, which uses the Hamiltonian $H=-2 J S_{1} S_{2} \cdot{ }^{47}$ The results of the fit are collected in Table 2. The two ferromagnetic compounds (6 and 7) were fitted taking into account intermolecular interactions $\left(z J^{\prime}\right)$, which improved the fit and reproduced the slight decrease of the $\chi_{\mathrm{M}} T$ values below $2.5 \mathrm{~K}$.

These results are in accord with the study reported by Gómez et al., where analogous compounds containing $\mu_{1,3}-n$ $\mathrm{RC}_{6} \mathrm{H}_{4} \mathrm{COO}^{-}$bridges show antiferromagnetic interactions whereas those with $\mu_{1,1}-n-\mathrm{RC}_{6} \mathrm{H}_{4} \mathrm{COO}^{-}$bridges display ferromagnetic interactions. ${ }^{26}$ The ferromagnetic interaction mediated by the $\mu_{1,1}$-bridge is principally observed in $\mathrm{Mn}^{\mathrm{II}}$ compounds having $\mathrm{Mn}-\left(\mu_{1,1}-\mathrm{O}\right)-\mathrm{Mn}$ angles of around $104^{\circ}$. However, other compounds with $\mathrm{Mn}-\mathrm{O}-\mathrm{Mn}$ angles ranging from $104^{\circ}$ to $108^{\circ}$ displaying antiferromagnetic behaviour have been reported. ${ }^{35,36,46}$

Trinuclear $\left[\mathrm{Mn}_{3}(\mathrm{NN})_{2}\left(\boldsymbol{\mu}-\boldsymbol{n}-\mathrm{RC}_{6} \mathrm{H}_{4} \mathrm{COO}\right)_{6}\right]$ compounds (11-14). $\chi_{\mathrm{M}} T$ versus $T$ plots for the trinuclear compounds are represented in Fig. 7. At $300 \mathrm{~K}, \chi_{\mathrm{M}} T$ values are close to the expected value for three uncoupled $\mathrm{Mn}^{\mathrm{II}}$ ions. As the temperature decreases, $\chi_{\mathrm{M}} T$ values fall until reaching $\sim 4.5 \mathrm{~cm}^{3} \mathrm{~mol}^{-1}$ $\mathrm{K}$ at $2 \mathrm{~K}$, which is very close to the expected value for an $S=$ $5 / 2$ ground state $\left(4.36 \mathrm{~cm}^{3} \mathrm{~mol}^{-1} \mathrm{~K}\right)$. This behaviour is indicative of an antiferromagnetic behaviour. The $S=5 / 2$ ground state is confirmed by the field dependence of the magnetisation at $2 \mathrm{~K}$ (inset of Fig. 7), which shows $M / N \mu_{\beta}$ values consistent with 5 unpaired electrons.

$\chi_{\mathrm{M}} T$ versus $T$ plots were fitted with the PHI program ${ }^{47}$ considering the Hamiltonian $H=-2 J\left(S_{1} S_{2}+S_{2} S_{3}\right)-2 J_{13}\left(S_{1} S_{3}\right)$ (see Fig. 8), where it is assumed that $J_{13}=0$ due to the large Mn...Mn distance between the terminal ions $(\sim 7.2 \AA)$. The results of these fits are collected in Table 3, these being consistent with those found in the literature for analogous trinuclear compounds. ${ }^{27,30,37-42}$ Moreover, the results obtained

Table 2 Magnetic parameters obtained from the fit of $\chi_{\mathrm{M}} T$ versus $T$ data for the dinuclear compounds with the formula $\left[\left\{M n(N N)_{2}\right\}_{2}(\mu-n-\right.$ $\left.\left.\mathrm{RC}_{6} \mathrm{H}_{4} \mathrm{COO}\right)_{2}\right]\left(\mathrm{ClO}_{4}\right)_{2}$

\begin{tabular}{lllll}
\hline & $g$ & $2 J^{a} / \mathrm{cm}^{-1}$ & $z J^{\prime} / \mathrm{cm}^{-1}$ & $R$ \\
\hline 1 & 2.02 & -2.4 & - & $1.0 \times 10^{-4}$ \\
2 & 2.02 & -2.0 & - & $2.5 \times 10^{-5}$ \\
3 & 2.03 & -1.4 & - & $1.9 \times 10^{-5}$ \\
$4^{c}$ & 2.02 & -1.9 & - & $2.0 \times 10^{-5}$ \\
5 & 2.00 & -2.0 & - & $3.8 \times 10^{-5}$ \\
6 & 2.02 & +1.1 & -0.002 & $3.3 \times 10^{-6}$ \\
7 & 2.01 & +1.3 & -0.001 & $9.2 \times 10^{-5}$
\end{tabular}

${ }^{a}$ Refers to $H=-2 J S_{1} S_{2}$, uncertainties of which were found to be smaller than $0.01 \mathrm{~cm}^{-1} .{ }^{b}$ Intermolecular interactions. ${ }^{c}$ Fitted considering TIP $=2 \times 10^{-3} \mathrm{~cm}^{3} \mathrm{~mol}^{-1} ; R=\sum\left[\left(\chi_{\mathrm{M}} T\right)_{\exp }-\left(\chi_{\mathrm{M}} T\right)_{\text {calcd }}\right]^{2} /$ $\sum\left[\left(\chi_{\mathrm{M}} T\right)_{\exp }\right]^{2}$. 


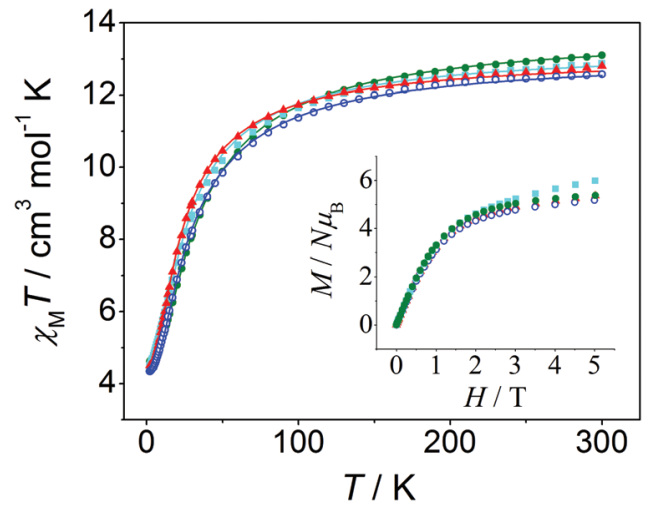

Fig. $7 \chi_{M} T$ versus $T$ and $M / N \mu_{\beta}$ versus $H$ plots (inset) for compounds 11 (red triangles), 12 (blue open circles), 13 (cyan squares), and 14 (green filled circles). The solid lines correspond to the best fit of the experimental data.

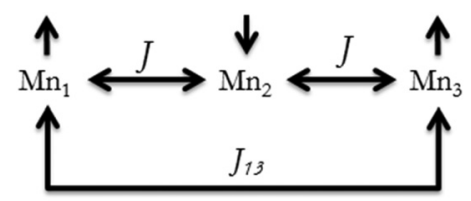

Fig. 8 Possible magnetic interactions in the linear trinuclear compounds.

Table 3 List of magnetic parameters obtained from the best fit of $\chi_{\mathrm{M}} T$ versus $T$ plots of the trinuclear compounds

\begin{tabular}{|c|c|c|c|c|}
\hline \multicolumn{2}{|c|}{ Compound } & \multirow{2}{*}{$\frac{g}{2.04}$} & \multirow{2}{*}{$\frac{2 J^{a} / \mathrm{cm}^{-1}}{-2.1}$} & \multirow{2}{*}{$\frac{R_{\mathrm{SUS}}}{5.9 \times 10^{-5}}$} \\
\hline 11 & 3-MeO/bpy & & & \\
\hline 12 & 4-MeO/bpy & 2.00 & -2.5 & $3.4 \times 10^{-5}$ \\
\hline 13 & 3-MeO/phen & 2.02 & -2.2 & $3.2 \times 10^{-4}$ \\
\hline 14 & 4-MeO/phen & 2.05 & -2.9 & $3.9 \times 10^{-5}$ \\
\hline
\end{tabular}

${ }^{a}$ Refers to $H=-2 J\left(S_{1} S_{2}+S_{2} S_{3}\right)-2 J_{13}\left(S_{1} S_{3}\right)$, with $J_{3}=0$, uncertainties of which were found to be smaller than $0.01 \mathrm{~cm}^{-1} ; R_{\mathrm{SUS}}=\sum\left[\left(\chi_{\mathrm{M}} T\right)_{\exp }-\right.$ $\left.\left(\chi_{\mathrm{M}} T\right)_{\text {calcd }}\right]^{2} / \sum\left[\left(\chi_{\mathrm{M}} T\right)_{\exp }\right]^{2}$.

for 12, with a marked $\mu_{1,1}$-mode of the carboxylate bridge and a weak antiferromagnetic interaction $\left(2 J=-2.5 \mathrm{~cm}^{-1}\right)$, are in agreement with the magneto-structural correlations previously reported. ${ }^{27}$ However, the structural data of the compounds reported here are too scarce to provide new insights into these correlations, since only the crystal structure of compound $\mathbf{1 2}$ could have been determined.

\section{EPR spectroscopy}

The X-band EPR spectra of all $\mathrm{Mn}^{\mathrm{II}}$ compounds herein reported (1-14) were recorded on powdered samples at different temperatures. At room temperature, all of them show a band centred at $g \approx 2$; however, the spectra become more complicated as the temperature falls. To exemplify, Fig. 9 shows the spectra at different temperatures for a dinuclear (5, $\left.4{ }^{-}{ }^{t} \mathrm{Bu} / \mathrm{phen}\right)$ and a trinuclear $(\mathbf{1 2}, 4-\mathrm{MeO} / \mathrm{bpy})$ compound.
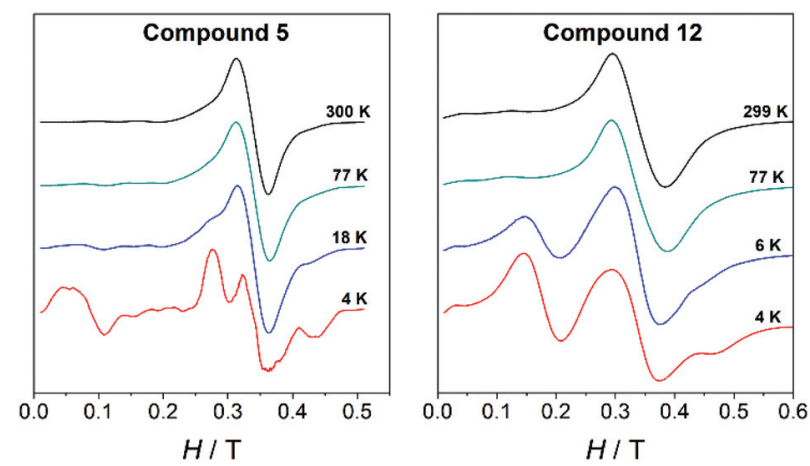

Fig. 9 Variable-temperature X-band EPR spectra for the dinuclear compound 5 and the trinuclear compound 12 .

At $4 \mathrm{~K}$, the spectra of each type of compound show peculiar features that allow its identification.

The fit of the EPR spectra was performed with the PHI program. ${ }^{47}$ It is worth noting that, even though this program is able to fit EPR spectra, the initial values from which the fit will begin are of importance for the final result. Hence, we performed several simulations screening different $D$ and $E$ values, within the logical range that one may expect for hexacoordinated $\mathrm{Mn}^{\mathrm{II}}$ ions, in order to choose the best initial values. All spectra were fitted considering a linewidth between 1.0 and $1.8 \mathrm{~cm}^{-1}$.

Mononuclear compounds (8-10). The EPR spectra at $4 \mathrm{~K}$ of the mononuclear compounds (8-10) are shown in Fig. 10. As may be observed, they show some differences.

The three compounds display a broad and intense band at $g \approx 2$ and more features more or less pronounced at lower

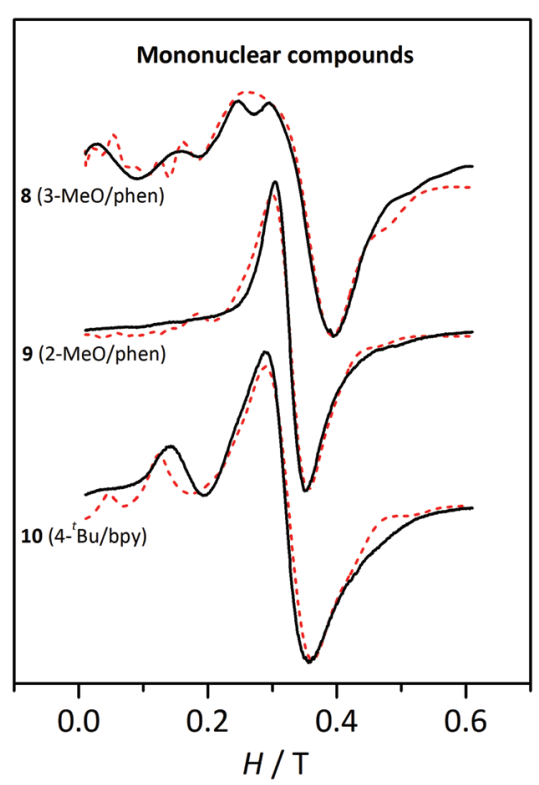

Fig. $10 \mathrm{X}$-band EPR spectra for the mononuclear compounds 8, 9, and 10 at $4 \mathrm{~K}$. The dashed lines correspond to the best fit of the experimental data. 
fields. These spectra were fitted with the PHI program ${ }^{47}$ considering a high-spin $\mathrm{Mn}^{\mathrm{II}}$ ion and the single-ion ZFS parameters $\left(D_{\mathrm{Mn}}\right.$ and $\left.E_{\mathrm{Mn}}\right)$. The results from these fits are listed in Table 4.

The $D_{\mathrm{Mn}}$ values obtained from these fits are consistent with $\mathrm{Mn}^{\mathrm{II}}$ ions with distorted octahedral geometry. ${ }^{24}$ Several simulations were performed by changing the sign of $D_{\mathrm{Mn}}$ and $E_{\mathrm{Mn}}$. While the shape of the spectra only depends on the $\left|E_{\mathrm{Mn}}\right|$, they vary with the sign and magnitude of $D_{\mathrm{Mn}}$. However, such differences were too small to unambiguously establish the sign of this parameter.

Dinuclear $\left[\left\{\mathrm{Mn}(\mathrm{NN})_{2}\right\}_{2}\left(\boldsymbol{\mu}-\boldsymbol{n}-\mathrm{RC}_{6} \mathrm{H}_{4} \mathrm{COO}\right)_{2}\right]\left(\mathrm{ClO}_{4}\right)_{2}$ compounds (1-7). For the dinuclear compounds the shape of the EPR spectra at low temperature depends on their magnetic behaviour (Fig. 11 and 12). While ferromagnetic compounds display a broad and intense signal at $g \approx 2$ at different temperatures, the antiferromagnetic compounds show much more complex spectra and their shape is very sensitive to temperature (Fig. S5 $\dagger$ ). These latter compounds show an $S=0$ ground state, so they are expected to be EPR silent. However, the small $J$ values allow the lowest excited states, $S=1$ and $S=2$, to be populated at $4 \mathrm{~K}$.

Table 4 Results from the fit of the EPR spectra of the three mononuclear compounds

\begin{tabular}{lllll}
\hline Compound & $g$ & $\left|D_{\mathrm{Mn}}\right| / \mathrm{cm}^{-1}$ & $\left|E_{\mathrm{Mn}}\right| / \mathrm{cm}^{-1}$ & $\left|E_{\mathrm{Mn}}\right| /\left|D_{\mathrm{Mn}}\right|$ \\
\hline $\mathbf{8}$ & 2.0 & 0.064 & 0.010 & 0.16 \\
$\mathbf{9}$ & 2.08 & 0.033 & 0.010 & 0.30 \\
$\mathbf{1 0}$ & 2.10 & 0.045 & 0.015 & 0.33
\end{tabular}

8, $\left[\mathrm{Mn}\left(\mathrm{H}_{2} \mathrm{O}\right)\left(3-\mathrm{MeOC}_{6} \mathrm{H}_{4} \mathrm{COO}\right)(\text { phen })_{2}\right]\left(\mathrm{ClO}_{4}\right) ; \quad$ 9, $\quad\left[\mathrm{Mn}\left(\mathrm{H}_{2} \mathrm{O}\right)_{2}(2-\right.$ $\left.\left.\mathrm{MeOC}_{6} \mathrm{H}_{4} \mathrm{COO}\right)_{2}(\mathrm{phen})\right] ; \mathbf{1 0},\left[\mathrm{Mn}(\mathrm{bpy})\left(4-{ }^{-} \mathrm{BuC}_{6} \mathrm{H}_{4} \mathrm{COO}\right)_{2}\left(\mathrm{H}_{2} \mathrm{O}\right)\right]$.

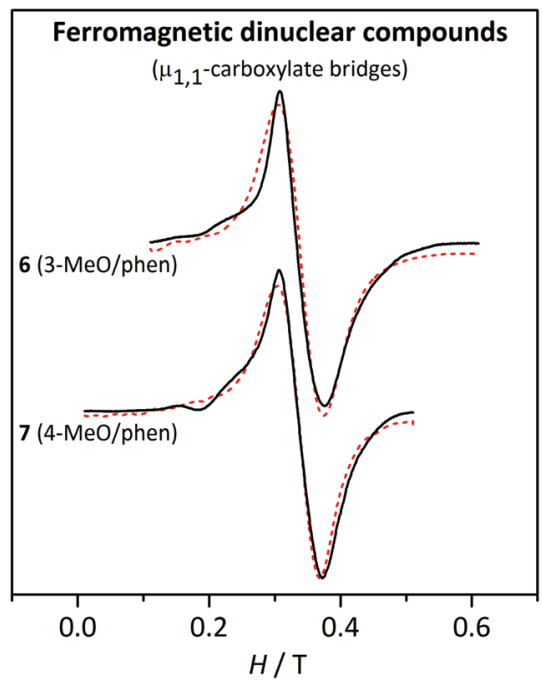

Fig. $11 \mathrm{X}$-band EPR spectra for the ferromagnetic dinuclear compounds 6 and 7 at $4 \mathrm{~K}$. The dashed lines correspond to the best fit of the experimental data.

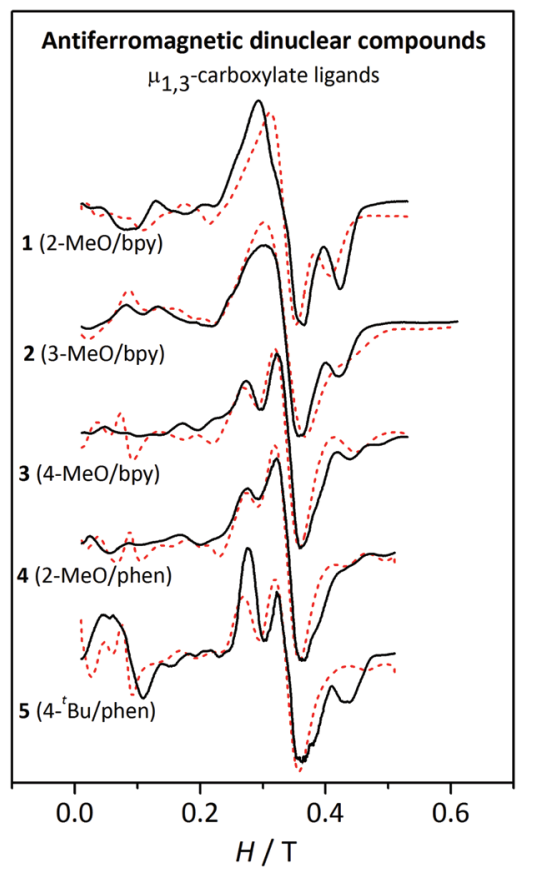

Fig. $12 \mathrm{X}$-band EPR spectra for the antiferromagnetic dinuclear compounds $1-5$ at $4 \mathrm{~K}$. The dashed lines correspond to the best fit of the experimental data.

The cause of the difference between the EPR spectra of anti- or ferromagnetic compounds relies on the values of the zero-field splitting parameters, $\left|D_{S}\right|$ and $\left|E_{S}\right|$, of the states populated at low temperature. In fact, $\left|D_{S}\right|$ and $\left|E_{S}\right|$ become smaller as the spin increases. ${ }^{48}$ Accordingly, the zero-field splitting parameters of the $S=5$ ground state of the ferromagnetic compounds are much smaller than those of the first excited states, $S=1$ and $S=2$, of the antiferromagnetic compounds.

The EPR spectra at $4 \mathrm{~K}$ of the dinuclear compounds were fitted with the PHI program ${ }^{47}$ with the aim of evaluating the single-ion ZFS parameters $\left(D_{\mathrm{Mn}}\right.$ and $\left.E_{\mathrm{Mn}}\right)$, considering two high-spin $\mathrm{Mn}^{\mathrm{II}}$ ions, with either parallel or antiparallel disposition of their spin moments, using the magnetic coupling constant $(2 J)$ obtained from the fit of the magnetic data, and keeping $g=2.00$. The results of these fits are collected in Table 5. Finding a good simulation of the EPR spectra of the

Table 5 Single-ion ZFS parameters obtained from the fit of the EPR spectra of the dinuclear compounds with the formula $\left[\left\{\mathrm{Mn}(\mathrm{NN})_{2}\right\}_{2}(\mu-n-\right.$ $\left.\left.\mathrm{RC}_{6} \mathrm{H}_{4} \mathrm{COO}\right)_{2}\right]\left(\mathrm{ClO}_{4}\right)_{2}$

\begin{tabular}{lllll}
\hline Compound & $2 J / \mathrm{cm}^{-1}$ & $D_{\mathrm{Mn}} / \mathrm{cm}^{-1}$ & $\left|E_{\mathrm{Mn}}\right| / \mathrm{cm}^{-1}$ & $\left|E_{\mathrm{Mn}}\right| /\left|D_{\mathrm{Mn}}\right|$ \\
\hline $\mathbf{1}$ & -2.4 & \pm 0.070 & 0.020 & 0.29 \\
$\mathbf{2}$ & -2.0 & \pm 0.083 & 0.017 & 0.20 \\
$\mathbf{3}$ & -1.4 & +0.125 & 0.006 & 0.05 \\
$\mathbf{4}$ & -1.9 & +0.104 & 0.013 & 0.13 \\
$\mathbf{5}$ & -2.0 & +0.121 & 0.017 & 0.14 \\
$\mathbf{6}$ & +1.1 & $\pm 0.030-0.048$ & $0.009-0.012$ & $0.19-0.33$ \\
$\mathbf{7}$ & +1.3 & $\pm 0.032-0.050$ & 0.009 & $0.18-0.28$
\end{tabular}


dinuclear compounds was far more complicated than that for the mononuclear ones. Indeed, before starting the fits, it was necessary to perform several simulations screening different $D_{\mathrm{Mn}}$ and $E_{\mathrm{Mn}} / D_{\mathrm{Mn}}$ values in order to find the best initial values for the fits.

For the ferromagnetic compounds 6 and 7, which display a single broad band (Fig. 11), the anisotropy parameters could not be determined with accuracy and, consequently, the results are expressed as a range. As mentioned above, the $D_{S=5}$ and $E_{S=5}$ parameters are smaller than the respective $D_{S<5}$ and $E_{S<5}$ for the same $D_{\mathrm{Mn}}$ and $E_{\mathrm{Mn}} \cdot{ }^{48}$ Hence, the EPR spectra at low temperature of a ferromagnetic $\mathrm{Mn}_{2}^{\mathrm{II}}$ compound, with $S=$ 5 ground state, will be much less sensitive to the ZFS parameters of the $\mathrm{Mn}^{\mathrm{II}}$ ions than the antiferromagnetic ones, where the first excited states, $S=1$ and $S=2$, are responsible for the splitting in the EPR signal. Indeed, while $D_{S=5} \approx$ $0.44 D_{\mathrm{Mn}}, D_{S=1} \approx-6.4 D_{\mathrm{Mn}}$ and $D_{S=2} \approx-0.95 D_{\mathrm{Mn}} \cdot{ }^{48}$ The $D_{\mathrm{Mn}}$ values obtained from the fit of the experimental data at $4 \mathrm{~K}$ are rather small $\left(\leq 0.05 \mathrm{~cm}^{-1}\right)$. Aiming to see the accuracy of these results, the shape of the spectra with different $D_{\mathrm{Mn}}$ and $E_{\mathrm{Mn}} / D_{\mathrm{Mn}}$ values was explored. As expected, no significant differences were found by changing the sign of $D_{\mathrm{Mn}}$. For $D_{\mathrm{Mn}}=$ $0.12 \mathrm{~cm}^{-1}$, strong bands are observed at low fields. When $D_{\mathrm{Mn}}=0.07 \mathrm{~cm}^{-1}$, the most intense features appear at $g \approx 2$, but a simple band, like the one in the experimental spectra, is only found when $D_{\mathrm{Mn}} \leq 0.5 \mathrm{~cm}^{-1}$ (Fig. S6 $\dagger$ ). Hence, in spite of the small effect of $D_{\mathrm{Mn}}$ on $D_{S=5}$, we can confirm that these compounds possess small single-ion ZFS parameters, as indicated in Table 5.

For these ferromagnetic compounds ( 6 and 7 ), the shape of the spectra is similar at different temperatures, with an increase of $0.02 \mathrm{~T}$ in the linewidth from $77 \mathrm{~K}$ to $4 \mathrm{~K}$. The simulation of the EPR spectra with the parameters obtained from the fit reproduces well the effect of temperature on the linewidth (Fig. S7†).

The spectra of compounds 1-5 at temperatures $>10 \mathrm{~K}$ are rather similar; however, at $4 \mathrm{~K}$ significant differences can be observed (Fig. 12). These spectra can be separated into three regions: (a) below $0.2 \mathrm{~T}$, where only 5 shows a significant band; (b) between 0.2-0.4 T, where compounds 1 and 2 show a unique broad band, while compounds 3-5 show two overlapped bands; and (c) above $0.4 \mathrm{~T}$, where compounds 1, 2, and 5 show a well-defined band. Owing to the intrinsic complexity of these spectra, fitting these spectra was far more challenging. The assignment of a particular set of values to the parameters was not trivial either, since the simulations obtained from the fit are far from being perfect. However, after screening different $D_{\mathrm{Mn}}$ and $E_{\mathrm{Mn}}$ values within the expected range for $\mathrm{Mn}^{\mathrm{II}}$ ions, the simulations presented in Fig. 12 correspond to those better representing the shape of the spectra.

Moreover, a surprising peculiarity was found: the sign of $D_{\text {Mn }}$ was certainly relevant for the shape of the EPR spectra of compounds 3, 4, and 5. A good fit of the EPR spectra of these compounds can only be attained with $D_{\mathrm{Mn}}>0$. These latter facts suggest that one may likely establish the sign of $D_{\mathrm{Mn}}$ in some precise situations. In order to understand the effect of the sign of $D_{\mathrm{Mn}}$ on the resulting EPR spectra, several simulations were performed with $g=2.00$ and $2 J=-2.4 \mathrm{~cm}^{-1}$ and two different $D_{\mathrm{Mn}}$ values and four different $E_{\mathrm{Mn}}$ values. Fig. 13 shows the spectra for these hypothetical dinuclear compounds.

As observed, for a "small" $D_{\mathrm{Mn}}$ value of $0.07 \mathrm{~cm}^{-1}$, the distinction between the spectra simulated with positive (red) or negative (blue) $D_{\mathrm{Mn}}$ appears very difficult to accomplish, since the bands are more or less situated in the same position and only the intensity differs. On the other hand, for a higher value $\left(\left|D_{\mathrm{Mn}}\right|=0.12 \mathrm{~cm}^{-1}\right)$, the differences between the spectra with positive or negative $D_{\mathrm{Mn}}$ become greater, as the bands do not only have different intensities but also appear at different fields. However, such variances become thinner as $E_{\mathrm{Mn}}$ increases, showing almost identical spectra when $\left|E_{\mathrm{Mn}}\right| /\left|D_{\mathrm{Mn}}\right|=0.33$. The sign of $D_{\mathrm{Mn}}$ is indeed very difficult to determine upon approaching the rhombic limit $(E / D=$ 0.33). ${ }^{49-51}$ To sum up, the degree of divergence between the spectra with positive and negative $D_{\mathrm{Mn}}$ depends on the magnitude of this parameter and the $\left|E_{\mathrm{Mn}}\right| /\left|D_{\mathrm{Mn}}\right|$ ratio: (a) the higher the $D_{\mathrm{Mn}}$ becomes, the more different the spectra are; and (b) the higher the $\left|E_{\mathrm{Mn}}\right| /\left|D_{\mathrm{Mn}}\right|$ ratio is, the less distinctive the spectra become.

To understand the cause of these latter points, a deeper analysis of the EPR spectra and Zeeman plots was performed. Firstly, it is worth recalling two important points: (a) in terms of populations the most relevant states are those with $S=0$ (ground state, which display no EPR transitions), $S=1$ (first excited state), and $S=2$ (second excited state), whose populations at $4 \mathrm{~K}$ are $\sim 66, \sim 28$, and $\sim 5 \%$, respectively; and (b) when the axial anisotropy $\left(D_{\mathrm{Mn}}\right)$ becomes relevant the Zeeman plot in the $z$ magnetic field direction is rather different from those in the $y$ and $x$ ones $(x=y \neq z)$, so the resulting EPR spectra come from the addition of the permitted transitions of the three Zeeman plots.

Therefore, the Zeeman plots in the $x / y$ and $z$ magnetic field directions for a hypothetical $\mathrm{Mn}_{2}^{\text {II }}$ system with $2 J=-2.4 \mathrm{~cm}^{-1}$
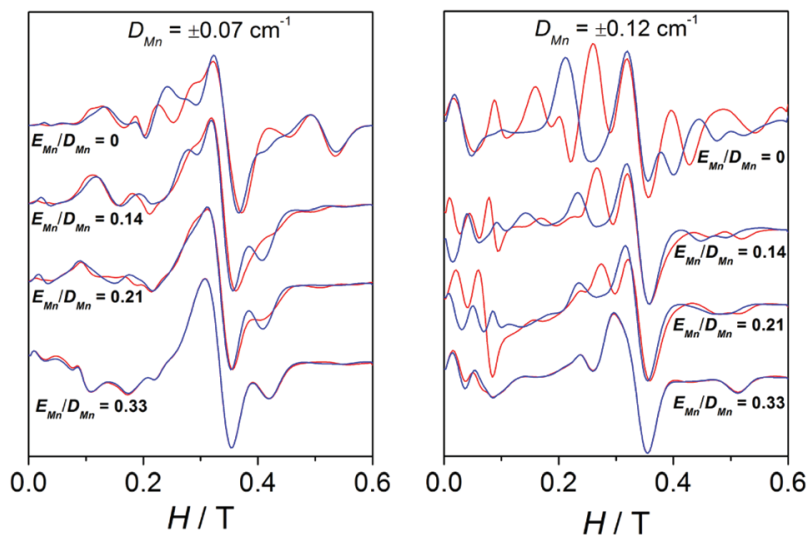

Fig. $13 \mathrm{X}$-band EPR spectra for a hypothetical dinuclear compound with $g=2.00$ and $2 \mathrm{~J}=-2.4 \mathrm{~cm}^{-1}$ for two different values of $D_{\mathrm{Mn}}$ and four different $\left|E_{\mathrm{Mn}}\right| /\left|D_{\mathrm{Mn}}\right|$ ratios. Red lines and blue lines correspond to the simulations performed with positive and negative $D_{M n}$, respectively. 
and $D_{\mathrm{Mn}}= \pm 0.12 \mathrm{~cm}^{-1}$ were simulated, and the expected transitions were marked according to the spectroscopic selection rules, $\Delta M_{S}= \pm 1$ and $\Delta S=0 .^{52}$ It is worth noting that no mixture of $M_{S}$ states coming from different $S$ levels was observed for $H<1.0 \mathrm{~T}$, so the EPR signals should come from the transitions between $M_{S}$ states within the same $S$ level. To simplify, the Zeeman plots of the first and second excited states were extracted from that calculated for the entire system and presented in two separated figures (Fig. 14 and 15). Fig. 14

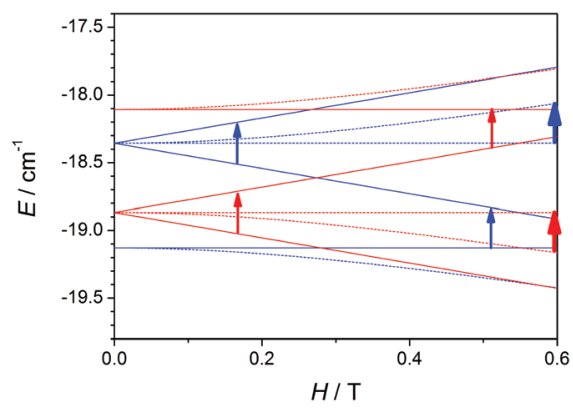

Fig. 14 Zeeman plots in the $x / y$ (dashed lines) and $z$ (straight lines) magnetic field directions for the first excited state $(S=1)$, extracted from a complete Zeeman plot calculated for a $M_{2}^{\|}$system with $2 \mathrm{~J}=$ $-2.4 \mathrm{~cm}^{-1}$ and positive (red) and negative (blue) ZFS $\left(D_{\mathrm{Mn}}= \pm 0.12 \mathrm{~cm}^{-1}\right)$. The arrows point out the expected transitions in the X-band EPR spectra. The transitions coming from the $x$ and $y$ magnetic field directions are represented by thicker arrows than those from the $z$ magnetic field direction because their contributions are double.

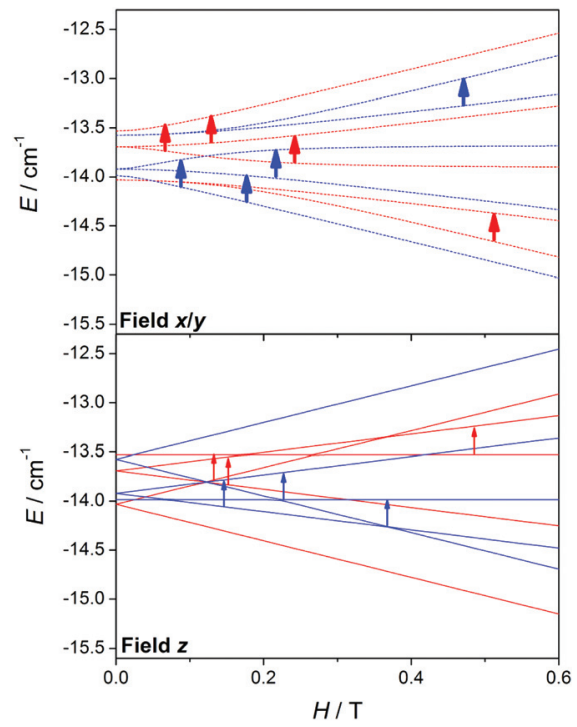

Fig. 15 Zeeman plots in the $x / y$ (dashed lines) and $z$ (straight lines) magnetic field directions for the second excited state $(S=2)$, extracted from a complete Zeeman plot calculated for a $\mathrm{Mn}_{2}^{\|}$system with $2 \mathrm{~J}=$ $-2.4 \mathrm{~cm}^{-1}$ and positive (red) and negative (blue) ZFS $\left(D_{\mathrm{Mn}}= \pm 0.12 \mathrm{~cm}^{-1}\right)$. The arrows point out the expected transitions in the X-band EPR spectra. The transitions coming from the $x$ and $y$ magnetic field directions are represented by thicker arrows than those from the $z$ direction because their contributions are double. shows the Zeeman plots in the $x / y$ and $z$ magnetic field directions of the first excited state, $S=1$, for a $\mathrm{Mn}_{2}^{\mathrm{II}}$ system with positive and negative $D_{\mathrm{Mn}}$. The pointed transitions correspond to those having $\Delta M_{S}=1$ (at $H=0.5-0.6 \mathrm{~T}$ ) and $\Delta M_{S}=2$ (at $H \approx$ $0.2 \mathrm{~T}$ ). These latter transitions should be forbidden according to the selection rules; however, when anisotropy is present, the $M_{S}$ states mix and that allows these transitions. ${ }^{48}$ As may be observed, the expected transitions should arise at the same field and should have the same intensity in both cases (for negative and positive $D_{\mathrm{Mn}}$ ). Hence, the cause of the difference between these spectra should lie in the second excited state $(S=2)$.

Fig. 15 shows the Zeeman plots in the $x / y$ and $z$ magnetic field directions of the second excited state, $S=2$, for a $\mathrm{Mn}_{2}^{\text {II }}$ system with positive and negative $D_{\mathrm{Mn}}$. Contrary to the $S=1$, the expected transitions coming from the $S=2$ are rather different in both position and intensity as a function of the sign of $D_{\mathrm{Mn}}$. These latter facts indicate that the differences between the spectra with positive and negative $D_{\mathrm{Mn}}$ rely on the transitions coming from the second excited state, $S=2$.

Another arising question is what dictates the sign of $D_{\mathrm{Mn}}$ in $\mathrm{Mn}^{\mathrm{II}}$ ions. As far as we know, there are several studies in the literature concerning the ZFS of $\mathrm{Mn}^{\mathrm{II}}$ ions; ${ }^{24,50,51,53,54}$ however, the factors determining the sign of $D_{\mathrm{Mn}}$ still remain unknown.

Trinuclear $\left[\mathrm{Mn}_{3}(\mathrm{NN})_{2}\left(\boldsymbol{\mu}-\boldsymbol{n}-\mathrm{RC}_{6} \mathrm{H}_{4} \mathrm{COO}\right)_{6}\right]$ compounds (11-14). The EPR spectra of the trinuclear compounds (11-14) are very sensitive to temperature. The spectra recorded at room temperature show a very broad band centred at $g \approx 2$. This band generally remains the most intense signal until very low temperatures. At $4 \mathrm{~K}$, the spectra of compounds 11, 12 and 14 become quite complicated: they show a new band at low field $(g \approx 4)$, of similar or major intensity compared to the band at $g \approx 2$, and some other features at high field (Fig. 16). The EPR spectrum at $4 \mathrm{~K}$ for compound $\mathbf{1 3}$ is quite different from the rest, showing the most intense band at $g \approx 2$ and a smaller one at low field.

Fitting the EPR spectra of the trinuclear compounds considering the whole system would be much more time-consuming, since each iteration takes about half an hour. So, in this case, the ZFS of the $\mathrm{Mn}^{\mathrm{II}}$ ions were not determined. As seen with the magnetic measurements, these compounds show an $S=5 / 2$ ground state. The first and second excited states, $S=$ $3 / 2$ and $S=7 / 2$, respectively, are found in the 5.5-7.3 and $7.6-10 \mathrm{~cm}^{-1}$ ranges, respectively, depending on the $2 J$ values. At $4 \mathrm{~K}$, the population of these states is quite low, being 6.5-11.2\% and $2.3-5.1 \%$ for the respective $S=3 / 2$ and $S=7 / 2$ states. Hence, at this temperature, the greatest contribution to the EPR spectra will be the ground state, whose population ranges from $\sim 80$ to $\sim 90 \%$.

Therefore, the spectra at $4 \mathrm{~K}$ were fitted using the PHI program $^{47}$ considering an isolated $S=5 / 2$ spin state with axial $\left(D_{5 / 2}\right)$ and rhombic $\left(E_{5 / 2}\right)$ ZFS, keeping $g=2.00$. Before fitting the experimental data, several simulations were carried out in order to identify which were the best initial values. The results of these fits, listed in Table 6, are in agreement with those reported for analogous compounds, whose $D_{5 / 2}$ and $E_{5 / 2}$ are 


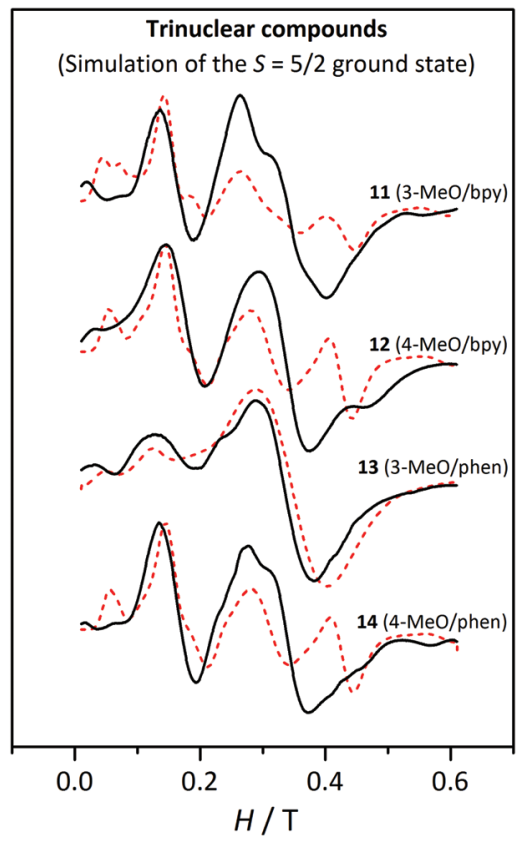

Fig. $16 \mathrm{X}$-band EPR spectra for the trinuclear compounds 11, 12, 13 and 14 at $4 \mathrm{~K}$. The dashed lines correspond to the best fit of the experimental data considering an isolated $S=5 / 2$ ground state.

Table 6 Results from the fit of the EPR spectra of the trinuclear compounds with the formula $\left[\mathrm{Mn}_{3}(\mathrm{NN})_{2}\left(\mu-n-\mathrm{RC}_{6} \mathrm{H}_{4} \mathrm{COO}\right)_{6}\right]$ considering an isolated $S=5 / 2$ ground state

\begin{tabular}{llll}
\hline Compound & $\left|D_{5 / 2}\right| / \mathrm{cm}^{-1}$ & $\left|E_{5 / 2}\right| / \mathrm{cm}^{-1}$ & $\left|E_{5 / 2}\right| /\left|D_{5 / 2}\right|$ \\
\hline $\mathbf{1 1}$ & 0.14 & 0.040 & 0.28 \\
$\mathbf{1 2}$ & 0.14 & 0.046 & 0.33 \\
$\mathbf{1 3}$ & 0.045 & 0.015 & 0.33 \\
$\mathbf{1 4}$ & 0.14 & 0.046 & 0.33
\end{tabular}

$\sim 0.16$ and $\sim 0.05 \mathrm{~cm}^{-1}$, respectively. ${ }^{27}$ Compound 13 displays much smaller ZFS parameters; however, the lack of structural data for this compound does not allow us to reach any conclusion. As observed in Fig. 16, only the fit for $\mathbf{1 3}$ corresponds to a good simulation of the experimental spectra. For the rest of the compounds, the theoretical graphs reproduce the band at $0.15 \mathrm{~T}$, but they show significant differences in the other regions of the spectra. Particularly, the intensity of the band at $g \approx 2$ for compounds $\mathbf{1 1}, \mathbf{1 2}$, and 14 seems to be underestimated, since it is much weaker in the fitted spectra (red dashed lines) than in the experimental ones (black line). Nevertheless, one should remember that these fits have been performed considering just the ground state and the greater intensity of these bands may be due to the excited states.

To explain this, the Zeeman plot for this kind of trinuclear compound was simulated considering $\left|D_{\mathrm{Mn}}\right|=0.1 \mathrm{~cm}^{-1}$ for the three $\mathrm{Mn}$ ions. The central ion, even though it is quite regular from the point of view of the angles (O6a-Mn2-O6, O4-Mn2$\mathrm{O} 4 \mathrm{a}$, and $\mathrm{O} 1-\mathrm{Mn} 2-\mathrm{O} 1 \mathrm{a}$ angles of $180^{\circ}$ ), shows a substantial elongation in the direction of the $\mu_{1,1}$-carboxylate ligand. From these calculations a relationship between the magnitudes of the ZFS parameters of each states could be found, where $D_{\mathrm{Mn}} \approx 0.64 D_{5 / 2}$ and $D_{5 / 2} \approx 0.95 D_{3 / 2} \approx 6.2 D_{7 / 2}$. So, while the two first states will have very similar $D$, the second excited state $(S=7 / 2)$ has a much smaller $D$ parameter. To confirm the effect of the population of the $S=7 / 2$ state on the shape of the graph, a new simulation was carried out for a system with an $S=7 / 2$ spin state, whose ZFS parameters are $D_{7 / 2}=0.025 \mathrm{~cm}^{-1}$ and $E_{7 / 2}=0.0075 \mathrm{~cm}^{-1}$ (equivalent to the fitted $D_{5 / 2}$ and $E_{5 / 2}$ parameters divided by 6 ). This spectrum displays just a broad and intense signal at $g \approx 2$. Hence, the higher intensity of this band in the experimental spectra of the trinuclear compounds may be due to a small contribution (population in the range $2.3-5.1 \%)$ of the second excited state $(S=7 / 2)$.

Simulations of the spectra of each compound were performed considering the entire molecule, including the magnetic coupling constant and the same $D_{\mathrm{Mn}}$ and $E_{\mathrm{Mn}}$ values for the three Mn(II) ions. $D_{\mathrm{Mn}}$ values were calculated from the $D_{5 / 2}$ values obtained from the fit (listed in Table 6), with the relationship obtained with the analysis of the Zeeman plots $\left(D_{\mathrm{Mn}}=0.64 D_{5 / 2}\right)$ (see above). Moreover, we assumed that the $E_{\mathrm{Mn}} / D_{\mathrm{Mn}}$ ratio is similar to the $E_{5 / 2} / D_{5 / 2}$ ratio. The parameters used for these simulations are listed in Table 7. They were performed for two different temperatures ( 4 and 60-80 K), considering the same linewidth and ZFS parameters. Fig. 17 shows these simulations at $4 \mathrm{~K}$. To exemplify, Fig. $\mathrm{S} 8 \dagger$ shows the experimental spectra and simulations at 4 and $60 \mathrm{~K}$ for compound 11. $\dagger$ From these simulations three remarkable conclusions could be drawn: (a) the simulation reproduces well the effect of temperature on the shape of the spectra; (b) no significant difference is observed by changing the sign of $D_{\mathrm{Mn}}$; and (c) the intensity of the bands at $g \approx 2$ for $\mathbf{1 1}, \mathbf{1 2}$, and 14 is well reproduced when the entire system is considered, confirming the contribution of the second excited state as suggested above.

As observed in Fig. 17, these simulations reproduce the experimental spectra much better. The differences between the spectra of $\mathbf{1 3}$ and the others $(\mathbf{1 1}, \mathbf{1 2}$, and 14) are a consequence of the different $D_{\mathrm{Mn}}$ values, which are significantly smaller for 13.

Even though the experimental spectra are much better reproduced when the entire system is considered and in spite of our efforts, the simulations for $\mathbf{1 2}$ and $\mathbf{1 4}$ show two bands,

Table 7 Parameters used for the simulation of the EPR spectra of the trinuclear compounds, with the formula $\left[\mathrm{Mn}_{3}(\mathrm{NN})_{2}\left(\mu-n-\mathrm{RC}_{6} \mathrm{H}_{4} \mathrm{COO}\right)_{6}\right]$, considering the entire trinuclear system

\begin{tabular}{lllll}
\hline Compound & $2 J^{a} / \mathrm{cm}^{-1}$ & $\left|D_{\mathrm{Mn}}\right| / \mathrm{cm}^{-1}$ & $\left|E_{\mathrm{Mn}}\right| / \mathrm{cm}^{-1}$ & $\left|E_{\mathrm{Mn}}\right| /\left|D_{\mathrm{Mn}}\right|$ \\
\hline $\mathbf{1 1}$ & -2.1 & 0.09 & 0.025 & 0.28 \\
$\mathbf{1 2}$ & -2.5 & 0.09 & 0.029 & 0.32 \\
$\mathbf{1 3}$ & -2.2 & 0.029 & 0.009 & 0.31 \\
$\mathbf{1 4}$ & -2.9 & 0.09 & 0.03 & 0.33
\end{tabular}

${ }^{a}$ Refers to the Hamiltonian $H=-2 J\left(S_{1} S_{2}+S_{2} S_{3}\right)-2 J_{13}\left(S_{1} S_{3}\right)$, consider$\operatorname{ing} J_{13}=0$. 


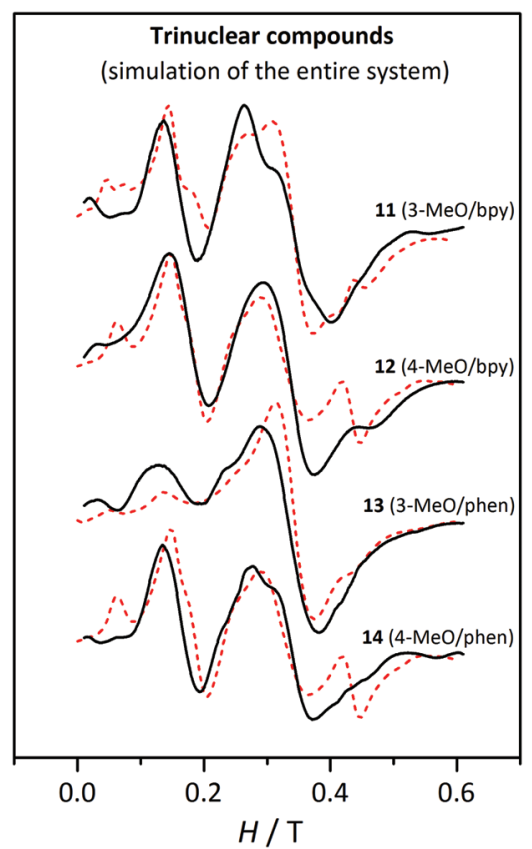

Fig. $17 \mathrm{X}$-band EPR spectra for the trinuclear compounds 11, 12, 13 and 14 at $4 \mathrm{~K}$. The dashed lines correspond to the simulation performed with the parameters listed in Table 7, considering the entire trinuclear system.

at $0.06 \mathrm{~T}$ and at $0.45 \mathrm{~T}$, that are not present in the experimental ones. Aiming to find an explanation, four new simulations were performed with $2 J=-2.0$ and $-3.0 \mathrm{~cm}^{-1}$, and $D_{\mathrm{Mn}}\left(E_{\mathrm{Mn}}\right)=$ 0.09 (0.03), and $0.03(0.01) \mathrm{cm}^{-1}$. From these simulations (presented in Fig. $\mathrm{S} 9 \dagger$ ) we concluded that: (a) the intensity of the bands at $g \approx 2$ decreases when the magnetic interaction is more antiferromagnetic; (b) the band at $0.15 \mathrm{~T}$ is intense when $D=0.09 \mathrm{~cm}^{-1}$ and is independent of the $2 J$ value; (c) the shoulder at $0.25 \mathrm{~T}$ is only detectable with $D=0.09 \mathrm{~cm}^{-1} ;(d)$ the band at $0.45 \mathrm{~T}$ is well defined when $D_{\mathrm{Mn}}=0.09 \mathrm{~cm}^{-1}$ and $E_{\mathrm{Mn}}=0.03 \mathrm{~cm}^{-1}$; and $(e)$ when $D=0.03 \mathrm{~cm}^{-1}$ the effect of the magnitude of the magnetic interaction is negligible.

With the aim of clarifying why the band at $0.45 \mathrm{~T}$ in the experimental spectra was not observed in the simulation, the effect of $E_{\mathrm{Mn}}$ was also analysed by performing simulations (shown in Fig. S10†) with the same $2 J=-3.0 \mathrm{~cm}^{-1}$ and $D_{\mathrm{Mn}}=$ $0.09 \mathrm{~cm}^{-1}$, and $E_{\mathrm{Mn}}=0.02,0.025$, and $0.03 \mathrm{~cm}^{-1}$. As may be observed, a small decrease of $E_{\mathrm{Mn}}$ changes the shape of the spectra substantially.

\section{Conclusions}

The reaction between $\mathrm{Mn}\left(n-\mathrm{RC}_{6} \mathrm{H}_{4} \mathrm{COO}\right)_{2}$, where $n-\mathrm{R}=2-\mathrm{MeO}$, 3-MeO, $4-\mathrm{MeO}$, or $4{ }^{t} \mathrm{Bu}$, and the NN ligands bpy and phen led to the formation of seven ionic dinuclear, three mononuclear (ionic or neutral), and four trinuclear compounds. Each type of compound was formed depending on the presence or absence of $\mathrm{ClO}_{4}{ }^{-}$ions, the solvent used, and/or the presence of a small amount of water in the reaction medium. Regarding the dinuclear compounds, two different types of complexes were obtained: those with $\mu_{1,1}$-carboxylate bridges, which present ferromagnetic behaviour, and those having $\mu_{1,3^{-}}$ carboxylate bridges, which show an antiferromagnetic interaction. The formation of compounds with the $\mu_{1,1}$-carboxylate bridges occurs when the $\mathrm{R}$ group is in meta $(n=3)$ or para $(n=4)$ position and phen is the blocking ligand. ${ }^{26}$ However, the voluminous $4-{ }^{t} \mathrm{Bu}$ group apparently hinders the formation of these $\mu_{1,1}$-bridges.

The EPR spectra of each type of compound give some peculiar features that allow its identification. All the EPR spectra presented in this work have been fitted in order to obtain the ZFS parameters, $D$ and $E$. However, fitting these spectra is not as easy as we expected, since many simulations had to be performed in order to choose the best initial values of the parameters willing to determine. In spite of these complications, fitting the spectra helped us to easily adjust the theoretical curves to the experimental ones after obtaining the approximate values.

The spectra of the antiferromagnetic dinuclear compounds are much more complex than those of the ferromagnetic ones, very likely because the ZFS parameter values of the states $\left(D_{S}\right.$ and $\left.E_{S}\right)$ populated at low temperature are higher for the antiferromagnetic systems. Moreover, the splitting of the bands in the antiferromagnetic compounds is eventually very sensitive to the sign of $D_{\mathrm{Mn}}$, particularly when $D_{\mathrm{Mn}}>0.10 \mathrm{~cm}^{-1}$ and the $\left|E_{\mathrm{Mn}}\right| /\left|D_{\mathrm{Mn}}\right|$ ratio is low. The analysis of the Zeeman plots revealed that the source of the difference between the spectra with positive and negative $D_{\mathrm{Mn}}$ lies in the second excited state $(S=2)$.

The shape of the EPR spectra at low temperature for the mononuclear and trinuclear complexes is different, in spite of showing the same $S=5 / 2$ ground state. For the trinuclear compounds, the relative intensity of the bands depends on the population in the excited states. The influence of the population in the second excited state $(S=7 / 2)$ could be seen with the intensity of the band at $g \approx 2$; this state has much smaller ZFS parameters than the ground and first excited states and contributes to the intensity of this $g \approx 2$ band.

Contrary to the mono- and dinuclear compounds, the EPR spectra of the trinuclear ones were fitted just considering the ZFS of the ground state. A relationship between the ZFS parameters of the states and those of the $\mathrm{Mn}^{\mathrm{II}}$ ion was then found from the analysis of the Zeeman plot of a trinuclear system. Therefore, the single-ion ZFS parameters could be estimated from those obtained just considering the ground state, giving a good simulation of the EPR spectra considering the entire system.

\section{Acknowledgements}

This work was supported by the Ministerio de Ciencia e Innovación of Spain (project no. CTQ2012-30662 and CTQ2015-63614-P). L. E. thanks the University of Barcelona for an APIF fellowship. 


\section{References}

1 S. J. Lippard and J. M. Berg, Principles of Bioinorganic Chemistry, University Science Books, 1994.

2 V. L. Schramm, Manganese in Metabolism and Enzyme Function, Elsevier, 2012.

3 H. Sigel, Metal Ions in Biological Systems: Volume 37: Manganese and Its Role in Biological Processes, CRC Press, 2000.

4 A.-F. Miller, Curr. Opin. Chem. Biol., 2004, 8, 162-168.

5 T. A. Jackson and T. C. Brunold, Acc. Chem. Res., 2004, 37, 461-470.

6 C. Buy, G. Girault and J.-L. Zimmermann, Biochemistry, 1996, 35, 9880-9891.

7 R. Kappl, K. Ranguelova, B. Koch, C. Duboc and J. Hüttermann, Magn. Reson. Chem., 2005, 43, S65-S73.

8 A. Murphy, G. Dubois and T. D. P. Stack, J. Am. Chem. Soc., 2003, 125, 5250-5251.

9 A. Murphy, A. Pace and T. D. P. Stack, Org. Lett., 2004, 6, 3119-3122.

10 A. Murphy and T. D. P. Stack, J. Mol. Catal. A: Chem., 2006, 251, 78-88.

11 I. Garcia-Bosch, A. Company, X. Fontrodona, X. Ribas and M. Costas, Org. Lett., 2008, 10, 2095-2098.

12 D. Pijper, P. Saisaha, J. W. de Boer, R. Hoen, C. Smit, A. Meetsma, R. Hage, R. P. van Summeren, P. L. Alsters, B. L. Feringa and W. R. Browne, Dalton Trans., 2010, 39, 10375.

13 D. M. L. Goodgame, H. E. Mkami, G. M. Smith, J. P. Zhao and E. J. L. McInnes, Dalton Trans., 2003, 34-35.

14 R. Boča, Coord. Chem. Rev., 2004, 248, 757-815.

15 R. B. Birdy and M. Goodgame, Inorg. Chim. Acta, 1981, 50, 183-187.

16 C. J. H. Jacobsen, E. Pedersen, J. Villadsen and H. Weihe, Inorg. Chem., 1993, 32, 1216-1221.

17 W. B. Lynch, R. S. Boorse and J. H. Freed, J. Am. Chem. Soc., 1993, 115, 10909-10915.

18 R. M. Wood, D. M. Stucker, L. M. Jones, W. B. Lynch, S. K. Misra and J. H. Freed, Inorg. Chem., 1999, 38, 53845388.

19 C. Mantel, C. Baffert, I. Romero, A. Deronzier, J. Pécaut, M.-N. Collomb and C. Duboc, Inorg. Chem., 2004, 43, 64556463.

20 C. Duboc, T. Phoeung, D. Jouvenot, A. G. Blackman, L. F. McClintock, J. Pécaut, M.-N. Collomb and A. Deronzier, Polyhedron, 2007, 26, 5243-5249.

21 C. Duboc, T. Phoeung, S. Zein, J. Pécaut, M.-N. Collomb and F. Neese, Inorg. Chem., 2007, 46, 4905-4916.

22 G. Berggren, P. Huang, L. Eriksson and M. F. Anderlund, Appl. Magn. Reson., 2009, 36, 9-24.

23 C. Mantel, C. Philouze, M.-N. Collomb and C. Duboc, Eur. J. Inorg. Chem., 2004, 2004, 3880-3886.

24 C. Duboc, M.-N. Collomb, J. Pécaut, A. Deronzier and F. Neese, Chem. - Eur. J., 2008, 14, 6498-6509.
25 J. Rich, C. E. Castillo, I. Romero, M. Rodríguez, C. Duboc and M.-N. Collomb, Eur. J. Inorg. Chem., 2010, 2010, 36583665.

26 V. Gómez, M. Corbella, M. Font-Bardia and T. Calvet, Dalton Trans., 2010, 39, 11664.

27 V. Gómez and M. Corbella, Eur. J. Inorg. Chem., 2009, 2009, 4471-4482.

28 SADABS, Version 2008/1, Sheldrick, Bruker AXS Inc., 2008.

29 G. M. Sheldrick, Acta Crystallogr., Sect. A: Fundam. Crystallogr., 2007, 64, 112-122.

30 G. Fernández, M. Corbella, J. Mahía and M. A. Maestro, Eur. J. Inorg. Chem., 2002, 2002, 2502-2510.

31 B. Albela, M. Corbella, J. Ribas, I. Castro, J. Sletten and H. Stoeckli-Evans, Inorg. Chem., 1998, 37, 788-798.

32 H. Oshio, E. Ino, I. Mogi and T. Ito, Inorg. Chem., 1993, 32, 5697-5703.

33 C. Ma, W. Wang, X. Zhang, C. Chen, Q. Liu, H. Zhu, D. Liao and L. Li, Eur. J. Inorg. Chem., 2004, 2004, 35223532.

34 Y.-S. Ma, X.-Y. Tang, F.-F. Xue, B. Chen, Y.-L. Dai, R.-X. Yuan and S. Roy, Eur. J. Inorg. Chem., 2012, 2012, 1243-1249.

35 S. Durot, C. Policar, G. Pelosi, F. Bisceglie, T. Mallah and J.-P. Mahy, Inorg. Chem., 2003, 42, 8072-8080.

36 D. Moon, J. Kim, M. Oh, B. J. Suh and M. S. Lah, Polyhedron, 2008, 27, 447-452.

37 S. G. Baca, I. L. Malaestean, T. D. Keene, H. Adams, M. D. Ward, J. Hauser, A. Neels and S. Decurtins, Inorg. Chem., 2008, 47, 11108-11119.

38 S. Menage, S. E. Vitols, P. Bergerat, E. Codjovi, O. Kahn, J. J. Girerd, M. Guillot, X. Solans and T. Calvet, Inorg. Chem., 1991, 30, 2666-2671.

39 V. Tangoulis, D. A. Malamatari, K. Soulti, V. Stergiou, C. P. Raptopoulou, A. Terzis, T. A. Kabanos and D. P. Kessissoglou, Inorg. Chem., 1996, 35, 4974-4983.

40 S. G. Baca, Y. Sevryugina, R. Clérac, I. Malaestean, N. Gerbeleu and M. A. Petrukhina, Inorg. Chem. Commun., 2005, 8, 474-478.

41 A. Escuer, B. Cordero, X. Solans, M. Font-Bardia and T. Calvet, Eur. J. Inorg. Chem., 2008, 2008, 5082-5087.

42 C. J. Milios, T. C. Stamatatos, P. Kyritsis, A. Terzis, C. P. Raptopoulou, R. Vicente, A. Escuer and S. P. Perlepes, Eur. J. Inorg. Chem., 2004, 2004, 2885-2901.

43 G. B. Deacon and R. J. Phillips, Coord. Chem. Rev., 1980, 33, 227-250.

44 V. Gómez and M. Corbella, J. Chem. Crystallogr., 2011, 41, 843-846.

45 V. Gómez, M. Corbella, F. A. Mautner, O. Roubeau, S. J. Teat, M. Font-Bardia and T. Calvet, Polyhedron, 2012, 45, 185-199.

46 F. Nepveu, N. Gaultier, N. Korber, J. Jaud and P. Castan, J. Chem. Soc., Dalton Trans., 1995, 4005-4013.

47 N. F. Chilton, R. P. Anderson, L. D. Turner, A. Soncini and K. S. Murray, J. Comput. Chem., 2013, 34, 11641175.

48 O. Kahn, Molecular magnetism, VCH, 1993. 
49 A. Abragam and B. Bleaney, Electron Paramagnetic Resonance of Transition Ions, OUP, Oxford, 2012.

50 S. Zein, C. Duboc, W. Lubitz and F. Neese, Inorg. Chem., 2008, 47, 134-142.

51 R. Carmieli, T. M. Larsen, G. H. Reed, S. Zein, F. Neese and D. Goldfarb, J. Am. Chem. Soc., 2007, 129, 4240-4252.
52 J. R. Gispert, Coordination Chemistry, Wiley, 2008.

53 S. C. Hunter, A. A. Podlesnyak and Z.-L. Xue, Inorg. Chem., 2014, 53, 1955-1961.

54 T. D. Tzima, G. Sioros, C. Duboc, D. Kovala-Demertzi, V. S. Melissas and Y. Sanakis, Polyhedron, 2009, 28, 32573264 . 